\title{
Fungal community assemblages in a high elevation desert environment: absence of dispersal \\ limitation and edaphic effects in surface soil
}

\author{
Teng Yang ${ }^{1,4}$, Jonathan M. Adams ${ }^{2}$, Yu Shi ${ }^{1}$, Huaibo Sun ${ }^{1}$, Liang Cheng ${ }^{1}$, \\ Yangjian Zhang ${ }^{3}$, Haiyan $\mathrm{Chu}^{1}{ }^{*}$
}

${ }^{1}$ State Key Laboratory of Soil and Sustainable Agriculture, Institute of Soil Science, Chinese Academy of Sciences, East Beijing Road 71, Nanjing 210008, China

${ }^{2}$ Division of Agrifood and Environment, School of Water, Energy and Environment, Cranfield University, Cranfield, Bedfordshire MK43 OAL, UK

${ }^{3}$ Key Laboratory of Ecosystem Network Observation and Modeling, Institute of Geographic Sciences and Natural Resources Research, Chinese Academy of Sciences, Beijing 100101, China.

${ }^{4}$ University of Chinese Academy of Sciences, Beijing 100049, China

*Corresponding author: Haiyan Chu

Corresponding address: State Key Laboratory of Soil and Sustainable Agriculture, Institute of Soil Science, Chinese Academy of Sciences, East Beijing Road 71, Nanjing 210008, China

Tel.: +862586881356, Fax: +8602586881000, E-mail: hychu@issas.ac.cn 


\begin{abstract}
Recent studies have shown the significant effects of environmental selection and possible dispersal limitation on soil fungal communities. However, less is known about the role of soil depth in fungal community assemblages, especially under soil environments that are intensely cold, infertile and water-deficient. In Ngari drylands of the Asiatic Plateau, we studied fungal assemblages at two soil depths, using Illumina sequencing of the ITS2 region for fungal identification (0-15 cm as the surface soil and $15-30 \mathrm{~cm}$ as the subsurface soil). Fungal diversity in the surface soil was much higher than that in the subsurface soil $(P<0.001)$, and communities differed significantly between the two layers $(P=0.001)$. Neither soil properties nor dispersal limitation could explain variation in the surface-soil fungal community. For the subsurface, by contrast, soil, climate and space explained $27 \%$ of variation in fungal community. Collectively, these results point to high dispersal rates and absence of edaphic effects in the surface-soil fungal community assemblage in Ngari drylands. It also suggests that for soil fungi with highly effective dispersal, regional distributions may fit with Bass-Becking's paradigm that 'Everything is everywhere'.
\end{abstract}

Keywords: fungal community assemblages, soil depth, Ngari drylands, high dispersal, environmental selection, null models.

\title{
Highlights
}

1. Fungal communities differed dramatically between surface and subsurface soils.

2. Surface soil had much higher fungal diversity than subsurface soil.

3. High dispersal contributed to the stochastic distribution of fungi in surface soil.

4. Space and environment structured fungal communities in subsurface soil. 


\section{Introduction}

While extreme cold desert environments may be characterized by paucity of soil nutrients, and challenging climates, they still produce abundant microbial populations (Treonis et al., 2002; Ziolkowski et al., 2013; Yadav et al., 2015), even though they may appear hostile to the most larger living organisms. Perhaps because of their faster evolutionary rates and higher genetic diversity (Whitman et al., 1998; Blackwell 2011; Li et al., 2014), microorganisms are more capable of adapting to harsh environments than macroorganisms, playing pivotal roles in biogeochemical cycling and ecosystem functioning (Yergeau et al., 2007; Chan et al., 2013). Recently, the diversity patterns and community assemblage processes of uncultured microorganisms in extreme environments have gained increasing attention. For example, Frossard et al. (2015) found that the intensity of wetting events and history of soil water regime had an interactive effect on soil microbial community composition in hot Namib Desert, while Shi et al. (2015) reported that soil microbial community composition was shaped by vegetation type on Arctic tundra. Recently, Cox et al. (2016) proposed that Antarctic soil fungal communities shared significantly more species with those in the distant Arctic, suggesting that a few fungal species with great dispersal ability are also able to colonize and dominate in cold and arid environments.

The Ngari region, which we focus on in this study, is located in the western Tibetan Plateau. It is characterized by severe cold, hyperaridity, strong wind and high ultraviolet radiation, and has been called the "arid core" of the Asiatic Plateau (Troll, 1972). Because of its remote location and harsh environments, few people enter this region, and correspondingly studies on its regional biodiversity are limited. The 1976 Interdisciplinary Scientific Expedition of the Chinese Academy of Sciences recorded 241 vascular plant species, and revealed the significant effects of climate, soil and space on plant community composition within the Ngari (Chang and Gauch, 1986). Recently, we reported the soil bacterial distribution in the Ngari, and also found that both environmental selection and dispersal limitation significantly influenced bacterial assemblages in the surface and subsurface soil layers (Chu et al., 2016).

Similarly to soil bacteria, fungi are also essential components of belowground biodiversity (Uroz et al., 2016; Peay et al., 2016), and their various functional guilds maintain a wide range of 
ecosystem processes, such as belowground carbon transportation (Klein et al., 2016), plant litter decomposition (Voriskova and Baldrian, 2013), controls on the coexistence and relative abundance of plant species (Lewis, 2010; Rudgers et al., 2010), and effects on plant growth (Parniske, 2008). Nevertheless, niche types, diversity patterns and community assemblage processes tend to differ between soil fungi and bacteria (Rousk et al., 2010; Geremia et al., 2016; Peay et al., 2016). Compared with bacteria, fungi are more capable of decomposing recalcitrant organic materials (Clipson et al., 2006), adapting to soil conditions of low nitrogen and high C:N ratio (Strickland and Rousk, 2010), and tolerating acidic soils (Rousk et al., 2009). As a follow-on from our recent study of soil bacterial distribution in the Ngari (Chu et al., 2016), a broad overview of the range of fungal communities is now appropriate.

High-throughput sequencing (HTS) provides fungal ecologists an efficient approach to studying soil fungal communities and their relationship to the surrounding environment (Lindahl et al., 2013; Balint et al., 2016). In recent and analogous broad scale studies, Shi et al. (2014) found that space, temperature and vegetation significantly affected soil fungal communities of forests in western China, while Pellissier et al. (2014) proposed that soil fungal communities of grasslands were mainly structured by soil properties, temperature and plant communities in the Western Swiss Alps. In an agricultural ecosystem in the black soil zone of northeast China, it was also reported that geographic distance and soil properties structured soil fungal communities (Liu et al., 2015). However, to our knowledge, regional scale studies on fungal community assemblages have rarely been carried out in both cold and hyperarid environments, such as Ngari (Pointing and Belnap, 2012). In this kind of special environment, soil depth may produce a stronger contrast of soil physicochemical and niche properties between the different layers: the surface soil may have higher nutrient availability and arrival of immigrant microbes, whereas the deeper soil may provide a more amenable environment for microbial activity, blocking the harmful UV radiation as well as extreme fluctuations in temperature and water potential. Therefore, based on the above suppositions, it is worth exploring how the fungal diversity, community composition and assembly process vary with soil depth. Moreover, taking into account soil depth can also help us to develop a more comprehensive understanding of soil fungal ecology in such an extreme environment, even 
though more than $50 \%$ of microbial biomass and biological activity occur in the surface soil for the most soil types (Tedersoo et al. 2014).

In this study, we used Illumina MiSeq platform to sequence fungal communities from samples taken at two soil depths (0-15 cm as the surface soil and $15-30 \mathrm{~cm}$ as the subsurface soil) at 13 sites in Ngari, Tibet. The horizontal distance between sites varied from $14 \mathrm{~km}$ to $925 \mathrm{~km}$. We addressed the difference in fungal diversity and community composition between different soil layers, as well as the relative roles of stochastic and deterministic processes in community assemblages between layers. Different community assemblage processes should prevail in the surface and subsurface soil. We hypothesize that stochastic processes should dominate fungal assemblages in the surface soil due to high dispersal in harsh environments (Favet et al., 2013; Itani and Smith, 2016), whereas deterministic processes may be expected to dominate fungal assemblages in the subsurface soil, considering its closed microhabitat and stable environment.

In addition, we proposed two ancillary hypotheses on diversity and community composition, respectively. One hypothesis was that fungal diversity is much lower in the subsurface soil relative to the surface soil, considering the reduced immigration and low nutrient availability in deeper soils. The other was that fungal community dissimilarity across the depth profile $(0-30 \mathrm{~cm})$ should be comparable to that found over large spatial distances (14-925 km), because niche differentiation caused by soil depth is expected to be at least as strong as any spatial effects of regional geographic distance occurring within the same layer of the desert soil.

\section{Materials and Methods}

\subsection{Soil sampling}

Soil samples were collected at 13 sites over a broad area $\left(\sim 300000 \mathrm{~km}^{2}\right)$ in western Tibet, China during July to August 2011 (Fig. 1). At each site, the surface soil (0-15 cm of depth) was collected from five random locations within a given square plot $(10 \mathrm{~m} \times 10 \mathrm{~m})$ and homogenized as a single soil sample, while the corresponding subsurface soil $(15-30 \mathrm{~cm}$ of depth) was collected simultaneously and then mixed as another soil sample within each site. All the samples collected in the field were packed in sterilized polyethylene bags, and transported to the lab in portable car 
refrigerators as quickly as possible. The twenty-six soil samples were then divided into two subsamples: One was stored at $4{ }^{\circ} \mathrm{C}$ to determine the soil properties, and the other was stored at $-80^{\circ} \mathrm{C}$ prior to DNA extraction.

\subsection{The collection of environmental data}

The environmental data included three geographic variables (latitude, longitude and elevation), four climatic variables (mean annual temperature-MAT, mean annual precipitationMAP, annual potential evapo-transpiration-PET and annual Aridity), and eight soil properties ( $\mathrm{pH}$, soil conductivity, soil moisture-SM, total soil carbon-TC, total soil nitrogen-TN, C:N ratio, dissolved organic carbon-DOC and dissolved total nitrogen-DTN). DTN is the sum of ammonium, nitrate and dissolved organic nitrogen. The measurement of soil properties was described in our recent study on soil bacterial communities (Chu et al., 2016), and soil conductivity was newly determined with a soil to water ratio of 1:5 by conductivity meter (Mettler Toledo FE30, Shanghai, China). MAT and MAP were compiled from the WorldClim database (www.worldclim.org) at 30 arc second resolution. PET and Aridity were obtained from CGIAR-CSI Global-Aridity and Global-PET database (http://www.cigar-csi.org). In addition, net primary productivity-NPP was compiled from the Atlas of the Biosphere (www.sage.wisc.edu/atlas/maps.php).

\subsection{DNA extraction and MiSeq sequencing}

Total DNA from each sample were extracted under sterile conditions from $0.5 \mathrm{~g}$ of soil by using a FastDNA ${ }^{\circledR}$ Spin kit (Bio 101, Carlsbad, CA, USA) according to the manufacturer's instruction, and stored at $-40^{\circ} \mathrm{C}$. Extracted DNA was diluted to approximately $25 \mathrm{ng} / \mu \mathrm{l}$ with sterilized distilled water and stored at $-20^{\circ} \mathrm{C}$ until use. Then the diluted DNA were frozen-transported to the Novogene Bioinformatics Technology Co., Ltd., Beijing, China, where they were defrosted, and analyzed using the Illumina MiSeq platform PE250 and the primers ITS3 (5'-GCATCGATGAAGAACGCAGC) / ITS4 (5'TCCTCCGCTTATTGATATGC) (White et al., 1990). Specifically, soil DNA were amplified by a T100 Thermal Cycler (Bio-rad, USA) in quadruplicate to alleviate environmental PCR bias. PCR system was $30 \mu \mathrm{l}$, including $15 \mu \mathrm{l}$ Phusion Master Mix (New England Biolabs, USA), $1.5 \mu \mathrm{l}$ each of $2 \mu \mathrm{M}$ forward and reverse primers, $10 \mu \mathrm{l}$ DNA template $\left(10 \mathrm{ng} \mu \mathrm{l}^{-1}\right)$ and $2 \mu \mathrm{l} \mathrm{H}_{2} \mathrm{O}$. PCR condition was 1 
min at $98^{\circ} \mathrm{C} ; 30$ cycles of $\left(10 \mathrm{~s}\right.$ at $98^{\circ} \mathrm{C} ; 30 \mathrm{~s}$ at $52{ }^{\circ} \mathrm{C} ; 30 \mathrm{~s}$ at $\left.72{ }^{\circ} \mathrm{C}\right) ; 5 \mathrm{~min}$ at $72{ }^{\circ} \mathrm{C}$. Length of the PCR amplicons was ca. $350 \mathrm{bp}$. Then we mixed equimolar PCR products to produce equivalent sequencing depth, and purified them by using GeneJET ${ }^{\mathrm{TM}}$ Gel Extraction Kit (Thermo Fisher Scientific Inc., USA). The amplicons' concentration was determined with a Qubit Fluorometer (Thermo Fisher Scientific Inc., USA). The library was constructed by using NEB Next ${ }^{\circledR}$ Ultra $^{\text {TM }}$ DNA Library Prep Kit for Illumina (New England Biolabs, USA). The sequence data associated with this study were submitted to the European Nucleotide Archive under the accession number PRJEB18012.

\subsection{Bioinformatics}

Paired-end reads from the original DNA fragments were merged using FLASH V1.2.7 (Magoc and Salzberg, 2011). The original quantity of reads was 1605 898. QIIME v. 1.9.0 (Caporaso et al., 2010) and cutadapt 1.9.1 (http://dx.doi.org/10.14806/ej.17.1.200) were used to quality filter, trim length, chimera check, cluster and assign sequences. It resulted in 1403192 high-quality reads after quality filter (parameters: minlength=280; maxambigs=0, and phred quality threshold=30). Then ITSx 1.0.11 (http://microbiology.se/software/itsx/) was used to remove the flanking large ribosomal subunit (LSU) and 5.8S genes according to the Users' guide (Bengtsson-Palme et al., 2013). We removed the putative chimeric sequences by using a combination of de novo and reference-based Chimera checking, with the flags --non_chimeras_rentention=union (Edgar et al., 2011). After that, the remaining sequences were clustered into operational taxonomic units (OTUs) at a $97 \%$ similarity threshold using the USEARCH algorithm (Edgar, 2010). All the singletons (clusters of size 1) were removed during the USEARCH clustering process, with the flags $-\mathrm{g} 2$, because some singletons represented artifacts or contaminants, and inflated alpha diversity erroneously (Kunin et al., 2010; Tedersoo et al., 2010). Taxonomy was assigned to fungal OTUs by rdp option in the parallel_assign_taxonmy_rdp.py with mini-confidence of 0.8 (Wang et al., 2007). The reference OTU database were the latest QIIME releases version from UNITE database (Version 7; http://unite.ut.ee). The "dynamic" representative/reference sequence file was used according to the recommendation of the manual (Koljalg et al., 2013). 104 OTUs (779 sequences) unassigned to fungi were removed prior to subsequent analysis. The final result was 1356770 fungal sequences 
(min: 22 466, max: 92 943, mean: 52 183) covering 5438 OTUs in 26 soil samples. In order to analyze the alpha and beta diversity of soil fungi at the same sequencing depth, the number of reads was rarefied to 22466 per sample.

\subsection{Statistics}

Based on the unrarefied OTU table, fungal community structure was summarized at the phylum level with summarize_taxa_through_plots.py script in QIIME. Significant differences in the relative abundance of Ascomycota, Basidiomycota, Chytridiomycota and Zygomycota between the surface and subsurface soil were tested with the Independent t-test using R stats package ( $R$ core team, 2017). Before the t-test, the original relative abundance data were arcsine-sqrt transformed to satisfy a normal distribution. We also manually blasted the ten most dominant OTUs in the surface and subsurface soil, respectively, in the GenBank Nucleotide database. Their putative taxonomic names and ecological niches were determined by the pre-stored information of specific GenBank Nos..

The observed OTUs and predicted Chao1 (Chao, 1984) were used to compare fungal alpha diversity between different soil layers. Significant differences in alpha diversity between the two layers were tested with the Independent t-test. Pearson correlation analyses were used to identify the environmental predictors of fungal richness in the two soil layers and for all soil samples using R psych package (Revelle, 2016). The original geographic variables (latitude, longitude and elevation) were not included in the tested environmental variables, because they have no direct effects on soil fungi, and indirectly affect fungal diversity by climate and soil properties (Pellissier et al., 2014; Delgado-Baquerizo et al., 2016). All the environmental variables and diversity indexes meet the criteria for normality and homogeneity of variances by Kolmogorov-Smirnov test and Levene's test, respectively, as implemented in SPSS Statistics 20.0 for windows (IBM-SPSS, Chicago, Illinois, USA).

In terms of fungal beta diversity, the rarefied OTU table was firstly Hellinger-transformed as in other studies (Shi et al., 2014; Balint et al., 2015), and Bray-Curtis dissimilarity index (BC) was calculated by function vegdist in R vegan package (Oksanen et al., 2017). Significant differences in Bray-Curtis dissimilarity among three groups (the dissimilarity between two soil layers within each 
site, the dissimilarity between different sites within the surface soil, and the dissimilarity between different sites within the subsurface soil) were tested with Games-Howell tests in SPSS Statistics 20.0. Non-metric multidimensional scaling analyses (NMDS) were performed with the metaMDS function in vegan package, and the ordiellipse function was employed to fit the ellipse lines at the confidence areas (0.95) by two soil layers onto the NMDS ordination. Significant differences in community composition between two soil layers were tested by permutational multivariate analysis of variance (Adonis) and analysis of similarity (ANOSIM) in vegan package.

The environmental dissimilarity was calculated based on Euclidean distance, and geographic distance was calculated based on latitude and longitude in PASSaGE2 (www.passagesoftware.net). We used Mantel tests to identify the environmental drivers of fungal community composition in the two soil layers and for all soil samples. The effects of geographic distance on the surface and subsurface soil fungal communities were tested by the distance decay model, that reflects the decrease in community similarity with increasing geographic distance (Nekola and White, 1999; Hanson et al., 2012). The similarity index was represented by 1-BC, where BC depicted Bray-Curtis dissimilarity index. Mantel tests were also used to examine the significant correlation between fungal communities and geographic distance in the surface and subsurface soil, respectively. In addition, we performed a multivariate analysis-variation partitioning analysis (VPA) to disentangle the effects of soil, climate and space on community composition in the surface and subsurface soil, respectively, as implemented with the function varpart in vegan package. Here, PCNM (principal coordinates of neighbour matrices) vectors with significant positive spatial autocorrelation were selected as the proxies of spatial variables (Borcard et al., 2011), and the variables from each part (i.e. soil, climate and space) were forward selected before VPA (McArdle and Anderson, 2001).

The modified Raup-Crick probability metric was used to infer the relative dominance of different community assemblage processes in the surface and subsurface soil, respectively (Chase et al., 2011). This measure compared the deviations in site-to-site dissimilarity from the stochastic null model expectations (3999 randomized matrices). The values ranging from -0.95 to -1 indicated high homogenizing dispersal. The values ranging from -0.95 to 0.95 indicated ecological drift, and 
the values ranging from 0.95 to 1 indicated environmental selection. Network-based visualization was performed to discern the relative proportions of the fungal cosmopolitan group (the presence in all sites), endemic group (the presence in one unique site) and shared group (the presence in 212 sites) in the surface and subsurface soil layers, respectively. The diagram was generated by Cytoscape 3.4.0 (Cline et al., 2007), and the layouts were based on the same algorithm (Kamada and Kawai, 1989). The OTUs' number and sequences' proportion of endemic group were compared between the surface and subsurface layers with the Independent t-test. For the shared group, the distribution range of every OTU was calculated based on the maximum distance between individuals of that OTU, as implemented with a Perl script (https://github.com/sunhuaibo/yangt_sbb/blob/master/shared_otu_range.pl). The distribution ranges of shared OTUs in the surface and subsurface soil were then displayed with a smooth density estimate and tested by the Independent t-test.

\section{Results}

\subsection{Data characteristics}

A total of 5438 fungal operational taxonomic units (OTUs, all are non-singletons) were retrieved from 1356770 high-quality ITS2 sequences in 26 soil samples. There were 856802 and 499968 reads in the surface and subsurface soil, respectively. The surface and subsurface soil each had 2925 and 796 exclusive OTUs, respectively. The number of shared OTUs between the two soil layers was 1717 (Fig. 1). The most abundant phylum was Ascomycota, accounting for more than $90 \%$ of total sequences, followed by Chytridiomycota $(\sim 1.9 \%)$, Basidiomycota $(\sim 1.3 \%)$ and Zygomycota ( 1.2\%). The relative abundance of Ascomycota in the subsurface soil was significantly higher than in the surface soil, while the relative abundances of Basidiomycota and Zygomycota in the surface soil were significantly higher than those in the subsurface soil (Table S1). Blast searches in GenBank for the most 17 abundant OTUs in the surface and subsurface soil showed that they were widely distributed in various habitats and across different continents (Table S2).

\subsection{Variation in diversity and community composition between soil layers}

Fungal richness in the surface soil was significantly higher than that in the subsurface soil 
$(P<0.001)$, and this soil depth-based trend was also statistically significant for predicted Chao1 (Fig. 2). Among the measured soil properties, DTN (dissolved total nitrogen) was significant different between the surface and subsurface layers ( $P=0.001$, Fig. S1 and Table S3), and fungal richness was significantly positive related to DTN for all samples (Pearson $r=0.69, P=0.001$ ). In the surface soil, $\mathrm{C}: \mathrm{N}$ ratio and PET (potential evapo-transpiration) showed the negative correlations with fungal richness, whereas no environmental variables were found to be related to fungal richness in the subsurface soil (Table S4).

An NMDS plot showed a clear differentiation in fungal communities between two soil layers (Fig. 3A), and a closer clustering of the points from within each soil layer, despite the large distances from 14 to 925 kilometers between each site within the same soil layer. Adonis analysis also corroborated that fungal community in the surface soil was significantly different from that in the subsurface soil $\left(R^{2}=0.23, P=0.001\right)$. In terms of pairwise Bray-Curtis dissimilarity, community dissimilarity between the two soil layers within each site $(0-15 \mathrm{~cm}$ vs $15-30 \mathrm{~cm}$, separated by a few centimeters), significantly exceeded that between different sites (spatially separated by many kilometers) in the surface layer (Fig. 3B). However, community dissimilarity between two soil layers within each site equaled that between different sites in the subsurface layer (Fig. 3B).

Mantel tests showed that C:N ratio and Aridity Index significantly affected the community composition for all 26 samples (Table S5). For surface-soil fungal communities, PET was an environmental driver, while soil conductivity, SM (soil moisture), TC (total carbon), C:N ratio, PET and Aridity drove the variation in fungal community in the subsurface soil (Table S5). With increasing geographic distance, community similarity did not significantly decrease in the surface soil, while community similarity significantly decreased with increasing geographic distance in the subsurface soil (Fig. 4). Variation partitioning analysis further confirmed that soil, climate and space cumulatively explained $27 \%$ of variation in subsurface-soil fungal communities, which was much greater than the explained variation in surface-soil fungal communities (Fig. S2).

\subsection{Different assemblage processes between soil layers}

Fungal community turnover (pairwise Bray-Curtis distance between each site) in the surface soil was significantly lower than that in the subsurface soil (Fig. 3B), and community dissimilarity 
between each site was significantly lower than expected by the null model (3999 randomized matrices) in the surface soil (Table 1A). Most of the Raup-Crick indexes were -1 , which reflected a strong homogenizing-mixing effect on surface-soil fungal assemblages due to high dispersal (Table 1A). In the subsurface layer, $29.5 \%$ of Raup-Crick indexes were between 0.95 and 1 , and $42.3 \%$ of indexes were between -0.95 and 0.95 , which indicated that environmental selection coupled with ecological drift was the main determinant for subsurface-soil fungal assemblages (Table 1B).

The network Venn diagram showed that the surface-soil samples (black points) converged at the center, with many shared OTUs (green points) and cosmopolitans (red points) surrounding them, whereas the subsurface-soil samples (black points) were dispersed with respect to sites, and each of them was individually surrounded by their endemic OTUs (yellow points) (Fig. 5A). Statistically, 132 OTUs (i.e. cosmopolitans) were distributed across all the sites in the surface layer, accounting for $60 \%$ of sequences. Oppositely, the number of cosmopolitans in the subsurface layer was only 4 , accounting for $9.6 \%$ of sequences (Fig. 5B). The proportion of endemic OTUs in subsurface was significantly larger than that in surface (Fig. 5C). In addition, the distribution range of OTUs shared among 2-12 sites was significantly larger in the surface soil relative to that in the subsurface soil $(P<0.001$, Fig. S3).

\section{Discussion}

We observed a sharp decline in fungal diversity from surface to subsurface soil layers, all across the region (Fig. 2). This was consistent with our hypothesis, which stated that fungal diversity is significantly lower in the subsurface soil than in the surface soil. The result was also in general agreement with the findings of fungal diversity change with soil depth in a local scale study of temperate forest (O' Brien et al., 2005), as well as in a glacier forefield (Rime et al., 2015). However, these trends have not been found in all environments. For example, Mueller et al. (2015) and Xiao et al. (2016) found that fungal richness was significantly higher in the deeper bulk soil relative to the surface soil in arid shrubland and arid grassland ecosystems, respectively. We reasoned that the deeper soil in those arid regions might provide more suitable micro-habitats for fungi, compared to the strong solar radiation influx and rapid drying of the surface parts of the soil. In 
addition, a continental scale study of soil fungal diversity in pine forest ecosystem did not reveal any significant difference in fungal richness with soil depth (Talbot et al., 2014), indicating that fungal diversity trends in relation to soil depth are also constrained by spatial scales.

In general, nutrient availability, fungal biomass and enzyme activities decrease with increasing soil depth (Stone et al., 2014; Sinsabaugh et al., 2015; Struecker and Joergensen, 2015; Grishkan and Kidron, 2016). In this study, the DTN (dissolved total nitrogen) content was significantly lower in the subsurface soil than in the surface soil, and a significant positive correlation was observed between fungal richness and DTN for all soil samples (Pearson $r=0.69, P=0.001$ ). C:N ratio was negatively related to fungal richness in the surface soil (Pearson $r=-0.57, P=0.043$ ), which was similar to our recent findings in alpine grasslands across the Tibetan Plateau (Yang et al., 2017) and another study in the maritime Antarctic (Newsham et al., 2016). The observed effects of DTN and $\mathrm{C}: \mathrm{N}$ ratio appear to suggest that soil nitrogen availability may be a limiting factor on fungal richness in Nagri drylands, which may be different from other arid regions. In addition, we reasoned that high dispersal intensity of fungal spores from other regions and within the sampled region may also enhance the fungal richness in the surface layer. Most of putative dominant fungi we found in the surface soil in our study had previously been observed in other regions located in different continents (Table S2), which was similar to the findings in the study of soil fungal communities in the North American Arctic (Timling et al., 2014). In terms of subsurface-soil fungal communities, it appears that the enclosed microhabitat blocks the immigration of exogenous fungal species, maintaining an ecologically specialized and less diverse local species pool.

Although our study region extended over $900 \mathrm{~km}$, fungal community composition differed significantly more between the two soil layers than between different sites, and no obvious variation of soil fungal communities was found between sites in the surface layer (Fig. 3A, Fig. 5A). This result was in general agreement with the description of soil fungal community composition in black spruce forests in interior Alaska (Taylor et al., 2014), which pointed to the very strong soilhorizon partitioning of fungal communities at the regional scale as well as the very uniform community composition in the surface soil. However, our results for fungi differ from our observations of soil bacterial distribution in the Ngari (Chu et al., 2016). The soil depth-based 
differences we observed in fungal communities were much stronger than had been the case for bacterial communities in the same soils (ANOSIM $R=0.67$ vs $R=0.37$ ), and interestingly fungal community dissimilarity between the surface and subsurface soil within each site exceeded that between different sites in the surface soil layer (Fig. 3B), which was also not found in our bacterial study (Chu et al., 2016). Within the same soil layer, different sites were in some cases more than $900 \mathrm{~km}$ distant, whereas pairwise soil samples collected from the same soil cores but different depth were less than thirty centimeters apart. This strongly suggests that for soil fungi in this environment, the niche differentiation seen between surface and deep soil in the same core is far greater than for surface samples hundreds of kilometers apart. In our study, soil depth explained $23 \%$ of variation in fungal community composition, while space, climate and measured soil properties accumulatively explained $10 \%$ of variation (Fig. S2). Similarly, in a study in southern California, Kivlin et al. (2014) found niche filtering rather than dispersal limitation had a dominant role in determining soil fungal community assemblages across a $40000 \mathrm{~km}^{2}$ regional landscape. Morrison-Whittle and Goddard (2015) proposed that niche differentiation explained four times more of the variation of fungal communities than geographic location across $1000 \mathrm{~km}$ in New Zealand. However, with further increasing geographic distance, it appears likely that broad-scale driving forces such as climate and dispersal limitation would prevail in affecting soil fungal assemblages (Tedersoo et al., 2014; Treseder et al., 2014), and thus the effect of soil depth may then appear relatively small. For example, a study on soil fungal communities across North American forests demonstrated that there was no significant difference in fungal community composition between the organic and mineral soil horizons at the continental scale (Talbot et al., 2014). McGuire et al. (2013) also found that fungal communities were most strongly differentiated by biome, between the boreal and tropical ecosystems, and comparatively weakly segregated by different soil horizons.

Previously in our study of the same region, bacterial community composition in both the surface and subsurface soil was found to be driven by shared environmental variables - total carbon and $\mathrm{C}: \mathrm{N}$ ratio, and geographic distance contributed equally to the variation in community composition in each of the two soil layers (Chu et al., 2016). In the present study, in the surface soil there was 
lack of any significant distance-decay relationship for fungal communities (Fig. 4), and none of the measured soil properties significantly affected fungal community composition (Table S5). Although the primary dispersal vectors should be similar for surface-soil bacterial and fungal communities, the differences in ecology (e.g. colonization capacity) between fungi and bacteria (Peay et al., 2016), and difference in the methodology (Miseq vs 454) might contribute to the different pattern in dispersal between this study and our previous study (Chu et al., 2016). This result also contrasts with the findings in many regional-scale studies, in which soil properties and geographic distance significantly affect fungal community composition (Bahram et al., 2013; Shi et al., 2014; Liu et al., 2015; Chen et al., 2017; Yang et al., 2017). However, other studies demonstrated the absence of a distance effect that might involve dispersal limitation for surface-soil fungal communities on the polar region (Geml et al., 2012; Timling et al., 2014; Cox et al., 2016). In addition, Favet et al. (2013) observed that various fungal species hitchhiked on dry dust in northern Chad to travel long distance across continents, and Itani and Smith (2016) reported that dust rains (i.e. wet deposition) delivered diverse fungal communities from arid regions of North Africa to the Eastern Mediterranean. By contrast, in the subsurface soil in our study, fungal community similarity decreased significantly with increasing geographic distance between sites $\left(R^{2}=0.43, P=0.001\right.$, Fig. 4), and soil, climate and spatial distance cumulatively explained $27 \%$ of variation in subsurface-soil fungal communities, which was more than four times of the amount of variation explained in surface-soil fungal communities (Fig. S2).

Consistent with our major hypothesis - that different community assemblage processes prevail in the surface and subsurface soil, respectively - we found statistical evidence of stochastic process with high dispersal prevailing in the surface soil, and deterministic process with edaphic, climatic and spatial effects dominant in the subsurface soil. In the surface soil layer, almost all the modified Raup-Crick dissimilarity indexes were -1 (Table $1 \mathrm{~A})$, which indicated that the fungal communities compared across sites were significantly more similar to one another than expected by random chance (Chase et al., 2011). Recently, Bahram et al. (2016) used this null-model method to infer a stochastic distribution of soil fungi due to high dispersal and drift in a cool temperate forest in Estonia. In their study, they proposed that values -1 represented the homogenizing effect of high 
dispersal. In general, the small-scale studies (e.g. Bahram et al., 2016), have two characteristics a narrow environmental gradient and short spatial distance between each sample locality. These two characteristics may be expected to cause stochastic processes to overwhelm deterministic processes (Wang et al., 2013). In the case of our study, one feature that was different from these previous studies was the very large spatial distance, over $900 \mathrm{~km}$. However, in our study too, the range of variation in environmental variables in the surface soil was not large (Table S3). The pH range across sites was between 8.2 and 9.0, and the MAP (mean annual precipitation) variation was $156-315 \mathrm{~mm} / \mathrm{yr}$. In addition, the sparse vegetation, loose topsoil and frequent dust storms (gale-force winds lasting more than 100 days/yr in Nagri) may mainly contribute to a high dispersal rate of fungal spores in the surface soil (Troll et al., 1972; Chang and Gauch, 1986; Qiu, 2014). Recently, Weil et al. (2017) found that whole microbial communities were transported from the Sahara to the Alps by desert dust storms, which strongly corroborates the hypothesis that extreme meteorological events can efficiently facilitate the long-distance dispersal of fungi and bacteria. In the present study, the surface-soil samples had an unusually large proportion of cosmopolitans, which accounted for $60 \%$ of sequence reads (Fig. 5B). The proportion of locally endemic OTUs in the surface soil was significantly smaller than in the subsurface soil (Fig. 5C). In addition, we found a significantly greater distribution range of shared OTUs in the surface layer than in the subsurface layer (Fig. S3).

The Baas-Becking hypothesis that "Everything is everywhere, but, the environment selects" is a famous microbiological tenet (Bass Becking, 1934), but the question has been raised whether microbes are really without dispersal limitation (Martiny et al., 2006; Hanson et al., 2012; Peay et al., 2016). For soil fungi, some studies have supported an effect of dispersal limitation, including examples of apparent endemism (Talbot et al., 2014), OTU-area relationships (Pellissier et al., 2014) and distance-decay relationships (Bahram et al., 2013; Meiser et al., 2014; Liu et al., 2015), whereas others have pointed to the absence of dispersal limitation and the existence of global fungal cosmopolitans (Timing et al., 2014; Davison et al., 2015; Cox et al., 2016; Itani and Smith, 2016). In fact, whether or not fungal community assemblages are predominantly affected by stochastic processes with high dispersal is apparently context-dependent and guild-dependent. 
Kilvin et al. (2014) provided evidence that dispersal rate of fungal spores differed between fungal taxa, and was affected by both stochastic and deterministic processes. Both endemic taxa and cosmopolitans should exist simultaneously, but their relative proportions may differ significantly among habitats and ecosystems. High dispersal efficiency has been expected to be more prevalent in extreme environments (Caruso et al., 2011; Favet et al., 2013; Timling et al., 2014; Cox et al., 2016), and (as we found here) in the surface soil layer rather than deeper soil layers.

\section{Conclusions}

In summary, we report here the striking pattern of community clustering based on soil depth rather than broad scale distance, and find that in this environment dispersal limitation does not structure fungal communities in the surface soil but does in the subsurface soil. Unlike the pattern observed for soil bacteria (Chu et al., 2016), fungal richness was three times greater in the surface soil than in the subsurface soil. Also, community dissimilarity between the surface and subsurface layers within each site (only $30 \mathrm{~cm}$ apart) significantly exceeded that between different sites in the surface layer that were between tens and hundreds of $\mathrm{km}$ apart. Soil depth explained more variation in community composition than the sum of spatial and environmental variables, which suggested the primary importance of niche differentiation in soil fungal assemblages.

Importantly, it appears that stochastic processes in the context of high dispersal rates predominated in the fungal community assemblages of the surface layer, whereas deterministic processes with respect to the effects of soil, climate and space were more important in subsurface soil fungal community assemblages. These results highlight the importance of stratified soil sampling in barren lands, if one is to form the comprehensive view of soil fungal biodiversity and biogeography. In addition, we suggest that in a windy and dry region with a lack of plant cover, surface-soil fungi with highly evolved dispersal spores may interfere with the emergence of regional endemism.

\section{Acknowledgements}

We thank Hongfei Wang, Yingying Ni, Congcong Shen and Xingjia Xiang for their assistance in lab analysis. This work was supported by the National Program on Key Basic Research Project 
(2014CB954002), the Strategic Priority Research Program (XDB15010101) of the Chinese Academy of Sciences, and the National Natural Science Foundation of China (41371254, 41701298). The authors declare no conflicts of interest.

\section{Reference}

Bahram, M., Kohout, P., Anslan, S., Harend, H., Abarenkov, K., Tedersoo, L., 2016. Stochastic distribution of small soil eukaryotes resulting from high dispersal and drift in a local environment. Isme Journal 10, 885-896.

Bahram, M., Koljalg, U., Courty, P.E., Diedhiou, A.G., Kjoller, R., Polme, S., Ryberg, M., Veldre, V., Tedersoo, L., 2013. The distance decay of similarity in communities of ectomycorrhizal fungi in different ecosystems and scales. Journal of Ecology 101, 1335-1344.

Balint, M., Bartha, L., O'Hara, R.B., Olson, M.S., Otte, J., Pfenninger, M., Robertson, A.L., Tiffin, P., Schmitt, I., 2015. Relocation, high-latitude warming and host genetic identity shape the foliar fungal microbiome of poplars. Molecular Ecology 24, 235-248.

Balint, M., Bahram, M., Eren, A.M., Faust, K., Fuhrman, J.A., Lindahl, B., O'Hara, R.B., Opik, M., Sogin, M.L., Unterseher, M., Tedersoo, L., 2016. Millions of reads, thousands of taxa: microbial community structure and associations analyzed via marker genes. FEMS Microbiol Rev 40, 686700.

Baas Becking, L.G.M., 1934. Geobiologie of inleiding tot de milieukunde. The Hague, the Netherlands: W.P. Van Stockum \& Zoon (in Dutch).

Bengtsson-Palme, J., Ryberg, M., Hartmann, M., Branco, S., Wang, Z., Godhe, A., De Wit, P., Sanchez-Garcia, M., Ebersberger, I., de Sousa, F., Amend, A.S., Jumpponen, A., Unterseher, M., Kristiansson, E., Abarenkov, K., Bertrand, Y.J.K., Sanli, K., Eriksson, K.M., Vik, U., Veldre, V., Nilsson, R.H., 2013. Improved software detection and extraction of ITS1 and ITS2 from ribosomal ITS sequences of fungi and other eukaryotes for analysis of environmental sequencing data. Methods in Ecology and Evolution 4, 914-919.

Blackwell, M., 2011. The Fungi: 1, 2, 3 ... 5.1 Million Species? American Journal of Botany 98, 426438.

Borcard D, Gillet FO, Legendre P., 2011. Numerical Ecology with R. Springer, New York. 
Caporaso, J.G., Kuczynski, J., Stombaugh, J., Bittinger, K., Bushman, F.D., Costello, E.K., Fierer, N., Pena, A.G., Goodrich, J.K., Gordon, J.I., Huttley, G.A., Kelley, S.T., Knights, D., Koenig, J.E., Ley, R.E., Lozupone, C.A., McDonald, D., Muegge, B.D., Pirrung, M., Reeder, J., Sevinsky, J.R., Tumbaugh, P.J., Walters, W.A., Widmann, J., Yatsunenko, T., Zaneveld, J., Knight, R., 2010. QIIME allows analysis of high-throughput community sequencing data. Nature Methods 7, 335-336.

Caruso, T., Chan, Y.K., Lacap, D.C., Lau, M.C.Y., Mckay, C.P., Pointing, S.B., 2011. Stochastic and deterministic processes interact in the assembly of desert microbial communities on a global scale. Isme Journal 5, 1406-1413.

Chan, Y.K., Van Nostrand, J.D., Zhou, J.Z., Pointing, S.B., Farrell, R.L., 2013. Functional ecology of an Antarctic Dry Valley. Proceedings of the National Academy of Sciences of the United States of America 110, 8990-8995.

Chang, D.H.S., Gauch, H.G., 1986. Multivariate Analysis of Plant Communities and Environmental Factors in Ngari, Tibet. Ecology 67, 1568-1575.

Chao, A., 1984 Nonparametric-Estimation of the Number of Classes in a Population. Scandinavian Journal of Statistics 11, 265-270.

Chase, J.M., Kraft, N.J.B., Smith, K.G., Vellend, M., Inouye, B.D., 2011. Using null models to disentangle variation in community dissimilarity from variation in alpha-diversity. Ecosphere 2, 111.

Chen, Y.L., Xu, T.L., Veresoglou, S.D., Hu, H.W., Hao, Z.P., Hu, Y.J., Hao, Z.P., Hu, Y.J., Liu, L., Deng, Y., Rillig, M.C., Chen, B.D., 2017 Plant diversity represents the prevalent determinant of soil fungal community structure across temperate grasslands in northern China. Soil Biology \& Biochemistry 110: $12-21$.

Chu, H.Y., Sun, H.B., Tripathi, B.M., Adams, J.M., Huang, R., Zhang, Y.J., Shi, Y., 2016. Bacterial community dissimilarity between the surface and subsurface soils equals horizontal differences over several kilometers in the western Tibetan Plateau. Environmental Microbiology 18, 15231533.

Cline, M.S., Smoot, M., Cerami, E., Kuchinsky, A., Landys, N., Workman, C., Christmas, R., AvilaCampilo, I., Creech, M., Gross, B., Hanspers, K., Isserlin, R., Kelley, R., Killcoyne, S., Lotia, S., 
Maere, S., Morris, J., Ono, K., Pavlovic, V., Pico, A.R., Vailaya, A., Wang, P.L., Adler, A., Conklin, B.R., Hood, L., Kuiper, M., Sander, C., Schmulevich, I., Schwikowski, B., Warner, G.J., Ideker, T., Bader, G.D., 2007. Integration of biological networks and gene expression data using Cytoscape. Nature Protocols 2, 2366-2382.

Clipson N, Otte M, Landy E., 2006. Biogeochemical roles of fungi in marine and estuarine habitats. In: Gadd G.M. (Eds.). Fungi in Biogeochemical Cycles. Cambridge University Press, CA, USA, pp. 436-461.

Cox, F., Newsham, K.K., Bol, R., Dungait, J.A.J., Robinson, C.H., 2016. Not poles apart: Antarctic soil fungal communities show similarities to those of the distant Arctic. Ecology Letters 19, 528536.

Davison, J., Moora, M., Opik, M., Adholeya, A., Ainsaar, L., Ba, A., Burla, S., Diedhiou, A.G., Hiiesalu, I., Jairus, T., Johnson, N.C., Kane, A., Koorem, K., Kochar, M., Ndiaye, C., Partel, M., Reier, U., Saks, U., Singh, R., Vasar, M., Zobel, M., 2015. FUNGAL SYMBIONTS Global assessment of arbuscular mycorrhizal fungus diversity reveals very low endemism. Science 349, 970-973. Delgado-Baquerizo, M., Maestre, F.T., Reich, P.B., Jeffries, T.C., Gaitan, J.J., Encinar, D., Berdugo, M., Campbell, C.D., Singh, B.K., 2016. Microbial diversity drives multifunctionality in terrestrial ecosystems. Nat Commun 7, 10541.

Dixon, P., 2003. VEGAN, a package of R functions for community ecology. Journal of Vegetation Science 14, 927-930.

Edgar, R.C., 2010. Search and clustering orders of magnitude faster than BLAST. Bioinformatics 26, $2460-2461$.

Edgar, R.C., Haas, B.J., Clemente, J.C., Quince, C., Knight, R., 2011. UCHIME improves sensitivity and speed of chimera detection. Bioinformatics 27, 2194-2200.

Favet, J., Lapanje, A., Giongo, A., Kennedy, S., Aung, Y.Y., Cattaneo, A., Davis-Richardson, A.G., Brown, C.T., Kort, R., Brumsack, H.J., Schnetger, B., Chappell, A., Kroijenga, J., Beck, A., Schwibbert, K., Mohamed, A.H., Kirchner, T., de Quadros, P.D., Triplett, E.W., Broughton, W.J., Gorbushina, A.A., 2013. Microbial hitchhikers on intercontinental dust: catching a lift in Chad. Isme Journal 7, 850-867. 
Frossard, A., Ramond, J.B., Seely, M., Cowan, D.A., 2015. Water regime history drives responses of soil Namib Desert microbial communities to wetting events. Scientific Reports 5, 12263. Geml, J., Timling, I., Robinson, C.H., Lennon, N., Nusbaum, H.C., Brochmann, C., Noordeloos, M.E., Taylor, D.L., 2012. An arctic community of symbiotic fungi assembled by long-distance dispersers: phylogenetic diversity of ectomycorrhizal basidiomycetes in Svalbard based on soil and sporocarp DNA. Journal of Biogeography 39, 74-88.

Geremia, R.A., Puscas, M., Zinger, L., Bonneville, J.M., Choler, P., 2016. Contrasting microbial biogeographical patterns between anthropogenic subalpine grasslands and natural alpine grasslands. New Phytologist 209, 1196-1207.

Grishkan, I., Kidron, G.J., 2016. Vertical Divergence of Cultured Microfungal Communities Through the Depth in Different Soil Formations at Nahal Nizzana, Western Negev Desert, Israel.

Geomicrobiology Journal 33, 564-577.

Hanson, C.A., Fuhrman, J.A., Horner-Devine, M.C., Martiny, J.B.H., 2012. Beyond biogeographic patterns: processes shaping the microbial landscape. Nature Reviews Microbiology 10, 497-506. Itani, G.N., Smith, C.A., 2016. Dust Rains Deliver Diverse Assemblages of Microorganisms to the Eastern Mediterranean. Scientific Reports 6, 22657.

Kamada, T., Kawai, S., 1989. An Algorithm for Drawing General Undirected Graphs. Information Processing Letters 31, 7-15.

Kivlin, S.N., Winston, G.C., Goulden, M.L., Treseder, K.K., 2014. Environmental filtering affects soil fungal community composition more than dispersal limitation at regional scales. Fungal Ecology $12,14-25$.

Klein, T., Siegwolf, R.T., Korner, C., 2016. Belowground carbon trade among tall trees in a temperate forest. Science 352, 342-344.

Koljalg, U., Nilsson, R.H., Abarenkov, K., Tedersoo, L., Taylor, A.F.S., Bahram, M., Bates, S.T., Bruns, T.D., Bengtsson-Palme, J., Callaghan, T.M., Douglas, B., Drenkhan, T., Eberhardt, U., Duenas, M., Grebenc, T., Griffith, G.W., Hartmann, M., Kirk, P.M., Kohout, P., Larsson, E., Lindahl, B.D., Luecking, R., Martin, M.P., Matheny, P.B., Nguyen, N.H., Niskanen, T., Oja, J., Peay, K.G., Peintner, U., Peterson, M., Poldmaa, K., Saag, L., Saar, I., Schuessler, A., Scott, J.A., Senes, C., Smith, M.E., 
Suija, A., Taylor, D.L., Telleria, M.T., Weiss, M., Larsson, K.H., 2013. Towards a unified paradigm for sequence-based identification of fungi. Molecular Ecology 22, 5271-5277.

Kunin, V., Engelbrektson, A., Ochman, H., Hugenholtz, P., 2010. Wrinkles in the rare biosphere: pyrosequencing errors can lead to artificial inflation of diversity estimates. Environmental Microbiology 12, 118-123.

Lewis, O.T., 2010. ECOLOGY Close relatives are bad news. Nature 466, 698-699.

Li, S.J., Hua, Z.S., Huang, L.N., Li, J., Shi, S.H., Chen, L.X., Kuang, J.L., Liu, J., Shu, W.S., 2014.

Microbial communities evolve faster in extreme environments. Scientific Reports 4, 6205.

Lindahl, B.D., Nilsson, R.H., Tedersoo, L., Abarenkov, K., Carlsen, T., Kjoller, R., Koljalg, U., Pennanen, T., Rosendahl, S., Stenlid, J., Kauserud, H., 2013. Fungal community analysis by highthroughput sequencing of amplified markers - a user's guide. New Phytologist 199, 288-299. Liu, J.J., Sui, Y.Y., Yu, Z.H., Shi, Y., Chu, H.Y., Jin, J., Liu, X.B., Wang, G.H., 2015. Soil carbon content drives the biogeographical distribution of fungal communities in the black soil zone of northeast China. Soil Biology \& Biochemistry 83, 29-39.

Maccario, L., Sanguino, L., Vogel, T.M., Larose, C., 2015. Snow and ice ecosystems: not so extreme. Res Microbiol 166, 782-795.

Magoc, T., Salzberg, S.L., 2011. FLASH: fast length adjustment of short reads to improve genome assemblies. Bioinformatics 27, 2957-2963.

Martiny, J.B.H., Bohannan, B.J.M., Brown, J.H., Colwell, R.K., Fuhrman, J.A., Green, J.L., HornerDevine, M.C., Kane, M., Krumins, J.A., Kuske, C.R., Morin, P.J., Naeem, S., Ovreas, L., Reysenbach, A.L., Smith, V.H., Staley, J.T., 2006. Microbial biogeography: putting microorganisms on the map. Nature Reviews Microbiology 4, 102-112.

McArdle, B.H., Anderson, M.J., 2001. Fitting multivariate models to community data: A comment on distance-based redundancy analysis. Ecology 82, 290-297.

McGuire, K.L., Allison, S.D., Fierer, N., Treseder, K.K., 2013. Ectomycorrhizal-Dominated Boreal and Tropical Forests Have Distinct Fungal Communities, but Analogous Spatial Patterns across Soil Horizons. Plos One 8, e68278.

Meiser, A., Balint, M., Schmitt, I., 2014. Meta-analysis of deep-sequenced fungal communities 
indicates limited taxon sharing between studies and the presence of biogeographic patterns. New Phytologist 201, 623-635.

Morrison-Whittle, P., Goddard, M.R., 2015. Quantifying the relative roles of selective and neutral processes in defining eukaryotic microbial communities. Isme Journal 9, 2003-2011.

Mueller, R.C., Belnap, J., Kuske, C.R., 2015. Soil bacterial and fungal community responses to nitrogen addition across soil depth and microhabitat in an arid shrubland. Frontiers in Microbiology 6, 891.

Nekola, J.C., White, P.S., 1999. The distance decay of similarity in biogeography and ecology. Journal of Biogeography 26, 867-878.

Newsham, K.K., Hopkins, D.W., Carvalhais, L.C., Fretwell, P.T., Rushton, S.P., O'Donnell, A.G., Dennis, P.G., 2016. Relationship between soil fungal diversity and temperature in the maritime Antarctic. Nature Climate Change 6, 182-186.

O'Brien, H.E., Parrent, J.L., Jackson, J.A., Moncalvo, J.M., Vilgalys, R., 2005. Fungal community analysis by large-scale sequencing of environmental samples. Appl Environ Microbiol 71, 55445550.

Oksanen, J., Blanchet, F.G., Friendly, M., Kindt, R., Legendre, P., McGlinn, D., Minchin, P.R., O'Hara, R.B., Simpson, G.L., Solymos, P., Stevens, M.H.H., Szoecs, E., Wagner, H., 2017. vegan: Community Ecology Package. R package version 2.4-3. https://CRAN.R-project.org/package=vegan.

Parniske, M., 2008. Arbuscular mycorrhiza: the mother of plant root endosymbioses. Nature Reviews Microbiology 6, 763-775.

Peay, K.G., Kennedy, P.G., Talbot, J.M., 2016. Dimensions of biodiversity in the Earth mycobiome. Nature Reviews Microbiology 14, 434-447.

Pellissier, L., Niculita-Hirzel, H., Dubuis, A., Pagni, M., Guex, N., Ndiribe, C., Salamin, N., Xenarios, I., Goudet, J., Sanders, I.R., Guisan, A., 2014. Soil fungal communities of grasslands are environmentally structured at a regional scale in the Alps. Molecular Ecology 23, 4274-4290. Pointing, S.B., Belnap, J., 2012. Microbial colonization and controls in dryland systems. Nature Reviews Microbiology 10, 551-562.

Qiu, J., 2014. Double threat for Tibet. Nature 512, 240-241. 
R Core Team, 2017. R: A language and environment for statistical computing. R Foundation for Statistical Computing, Vienna, Austria. URL https://www.R-project.org/.

Revelle, W., 2016 psych: Procedures for Personality and Psychological Research, Northwestern University, Evanston, Illinois, USA, https://CRAN.R-project.org/package=psych Version = 1.6.9. Rime, T., Hartmann, M., Brunner, I., Widmer, F., Zeyer, J., Frey, B., 2015. Vertical distribution of the soil microbiota along a successional gradient in a glacier forefield. Molecular Ecology 24, 10911108.

Rousk, J., Brookes, P.C., Baath, E., 2009. Contrasting Soil pH Effects on Fungal and Bacterial Growth Suggest Functional Redundancy in Carbon Mineralization. Appl Environ Microbiol 75, 1589-1596.

Rousk, J., Baath, E., Brookes, P.C., Lauber, C.L., Lozupone, C., Caporaso, J.G., Knight, R., Fierer, N., 2010. Soil bacterial and fungal communities across a pH gradient in an arable soil. Isme Journal 4 , $1340-1351$

Rudgers, J.A., Fischer, S., Clay, K., 2010 Managing plant symbiosis: fungal endophyte genotype alters plant community composition. Journal of Applied Ecology 47, 468-477.

Shi, L.L., Mortimer, P.E., Slik, J.W.F., Zou, X.M., Xu, J.C., Feng, W.T., Qiao, L., 2014. Variation in forest soil fungal diversity along a latitudinal gradient. Fungal Diversity 64, 305-315.

Shi, Y., Grogan, P., Sun, H.B., Xiong, J.B., Yang, Y.F., Zhou, J.Z., Chu, H.Y., 2015. Multi-scale variability analysis reveals the importance of spatial distance in shaping Arctic soil microbial functional communities. Soil Biology \& Biochemistry 86, 126-134.

Sinsabaugh, R.L., Belnap, J., Rudgers, J., Kuske, C.R., Martinez, N., Sandquist, D., 2015. Soil microbial responses to nitrogen addition in arid ecosystems. Frontiers in Microbiology 6, 819. Stone, M.M., DeForest, J.L., Plante, A.F., 2014. Changes in extracellular enzyme activity and microbial community structure with soil depth at the Luquillo Critical Zone Observatory. Soil Biology \& Biochemistry 75, 237-247.

Strickland, M.S., Rousk, J., 2010. Considering fungal:bacterial dominance in soils - Methods, controls, and ecosystem implications. Soil Biology \& Biochemistry 42, 1385-1395. Struecker, J., Joergensen, R.G., 2015. Microorganisms and their substrate utilization patterns in 
topsoil and subsoil layers of two silt barns, differing in soil organic $\mathrm{C}$ accumulation due to colluvial processes. Soil Biology \& Biochemistry 91, 310-317.

Talbot, J.M., Bruns, T.D., Taylor, J.W., Smith, D.P., Branco, S., Glassman, S.I., Erlandson, S., Vilgalys, R., Liao, H.L., Smith, M.E., Peay, K.G., 2014. Endemism and functional convergence across the North American soil mycobiome. Proceedings of the National Academy of Sciences of the United States of America 111, 6341-6346.

Taylor, D.L., Hollingsworth, T.N., McFarland, J.W., Lennon, N.J., Nusbaum, C., Ruess, R.W., 2014. A first comprehensive census of fungi in soil reveals both hyperdiversity and fine-scale niche partitioning. Ecological Monographs 84, 3-20.

Tedersoo, L., Nilsson, R.H., Abarenkov, K., Jairus, T., Sadam, A., Saar, I., Bahram, M., Bechem, E., Chuyong, G., Koljalg, U., 2010. 454 Pyrosequencing and Sanger sequencing of tropical mycorrhizal fungi provide similar results but reveal substantial methodological biases. New Phytologist 188, 291-301.

Tedersoo, L., Bahram, M., Polme, S., Koljalg, U., Yorou, N.S., Wijesundera, R., Villarreal Ruiz, L., Vasco-Palacios, A.M., Thu, P.Q., Suija, A., Smith, M.E., Sharp, C., Saluveer, E., Saitta, A., Rosas, M., Riit, T., Ratkowsky, D., Pritsch, K., Poldmaa, K., Piepenbring, M., Phosri, C., Peterson, M., Parts, K., Partel, K., Otsing, E., Nouhra, E., Njouonkou, A.L., Nilsson, R.H., Morgado, L.N., Mayor, J., May, T.W., Majuakim, L., Lodge, D.J., Lee, S.S., Larsson, K.H., Kohout, P., Hosaka, K., Hiiesalu, I., Henkel, T.W., Harend, H., Guo, L.D., Greslebin, A., Grelet, G., Geml, J., Gates, G., Dunstan, W., Dunk, C., Drenkhan, R., Dearnaley, J., De Kesel, A., Dang, T., Chen, X., Buegger, F., Brearley, F.Q., Bonito, G., Anslan, S., Abell, S., Abarenkov, K., 2014. Fungal biogeography. Global diversity and geography of soil fungi. Science 346, 1256688.

Timling, I., Walker, D.A., Nusbaum, C., Lennon, N.J., Taylor, D.L., 2014. Rich and cold: diversity, distribution and drivers of fungal communities in patterned-ground ecosystems of the North American Arctic. Molecular Ecology 23, 3258-3272.

Treonis, A.M., Wall, D.H., Virginia, R.A., 2002. Field and microcosm studies of decomposition and soil biota in a cold desert soil. Ecosystems 5, 159-170.

Treseder, K.K., Maltz, M.R., Hawkins, B.A., Fierer, N., Stajich, J.E., McGuire, K.L., 2014. 
Evolutionary histories of soil fungi are reflected in their large-scale biogeography. Ecology Letters $17,1086-1093$.

Troll, C., 1972. The three-dimensional zonation of the Himalaya system. In: Troll, C. (Eds.), Geoecology of the High Mountain Regions in Eurasia. Vol. 4. Wiesbaden, Germany:

Erdwissenschaftliche Forschung. Franz Steiner Verlag, pp. 264-275.

Uroz, S., Buée, M., Deveau, A., Mieszkin, S., Martin, F., 2016. Ecology of the forest microbiome: Highlights of temperate and boreal ecosystems. Soil Biology and Biochemistry 103, 471-488. Voriskova, J., Baldrian, P., 2013. Fungal community on decomposing leaf litter undergoes rapid successional changes. Isme Journal 7, 477-486.

Wang, J.J., Shen, J., Wu, Y.C., Tu, C., Soininen, J., Stegen, J.C., He, J.Z., Liu, X.Q., Zhang, L., Zhang, E.L., 2013. Phylogenetic beta diversity in bacterial assemblages across ecosystems: deterministic versus stochastic processes. Isme Journal 7, 1310-1321.

Wang, Q., Garrity, G.M., Tiedje, J.M., Cole, J.R., 2007. Naive Bayesian classifier for rapid assignment of rRNA sequences into the new bacterial taxonomy. Appl Environ Microbiol 73, 5261-5267.

White T.J., Bruns T.D., Lee S., Taylor J.. 1990. Analysis of phylogenetic relationships by amplification and direct sequencing of ribosomal RNA genes. In: Innis M.A., Gelfand D.N., Sninsky J.J., White T.J., (Eds.) PCR Protocols: A Guide to Methods and Applications. New York, NY, USA, Academic Press, pp. 315-322.

Whitman, W.B., Coleman, D.C., Wiebe, W.J., 1998. Prokaryotes: The unseen majority. Proceedings of the National Academy of Sciences of the United States of America 95, 6578-6583.

Yadav, A.N., Sachan, S.G., Verma, P., Tyagi, S.P., Kaushik, R., Saxena, A.K., 2015. Culturable diversity and functional annotation of psychrotrophic bacteria from cold desert of Leh Ladakh (India). World Journal of Microbiology \& Biotechnology 31, 95-108.

Yang, T., Adams, J.M., Shi, Y., He, J.S., Jing, X., Chen, L.T., Tedersoo, L., Chu, H.Y., 2017. Soil fungal diversity in natural grasslands of the Tibetan Plateau: associations with plant diversity and productivity. New Phytologist 215, 756-765.

Yergeau, E., Kang, S., He, Z., Zhou, J., Kowalchuk, G.A., 2007. Functional microarray analysis of 
nitrogen and carbon cycling genes across an Antarctic latitudinal transect. Isme Journal 1,163179.

Ziolkowski, L.A., Mykytczuk, N.C.S., Omelon, C.R., Johnson, H., Whyte, L.G., Slater, G.F., 2013. Arctic gypsum endoliths: a biogeochemical characterization of a viable and active microbial community. Biogeosciences 10, 7661-7675. 


\section{Figure legends}

Fig. 1. (A) Total fungal diversity (number of observed OTUs) between the surface and subsurface layers and their overlap. (B) The thirteen study sites in Ngari, Tibet. (C) Relative abundance of four fungal phyla for all the 26 samples (All), the surface-soil samples (Surface) and the subsurface-soil samples (Subsurface).

Fig. 2. Fungal alpha diversity between the surface and subsurface soil. The asterisk means the significant difference in fungal alpha diversity between the two soil layers.

Fig. 3. Fungal community composition between the surface and subsurface soil. (A) Twodimensional ordination using NMDS, based on the average Bray-Curtis dissimilarity matrix, computed from 26 rarefied and hellinger-transformed sites×OTUs matrices. The purple squares represented the subsurface-soil samples, and the green squares represented the surface-soil samples. Two ellipses represented the confidence areas (0.95) of the subsurface and surface layers. (B) The comparison of Bray-Curtis dissimilarity among three groups. "Surface vs Subsurface" means the community dissimilarity between the surface and subsurface soil samples within each site, and "Within Surface" (or "Within Subsurface") means the community dissimilarity between pairwise sites in the surface (or subsurface) soil layers. Of note, "Within Surface(-1)" means the community dissimilarity between pairwise sites in the surface-soil samples after removing one outlier.

Fig. 4. The distance-decay pattern for fungal community similarity in the surface and subsurface soil. The correlation between fungal community dissimilarity and geographic distance was not significant in the surface soil (Mantel $r=0.142, P=0.181$ ), and the correlation between fungal 
community dissimilarity and geographic distance was significant positive in the subsurface soil

(Mantel $\mathrm{r}=0.659, P=0.001$ ).

Fig. 5. The network analysis on the fungal OTUs in the surface and subsurface soil. Each point represented one independent OTU except that the black points represented soil samples. Red color represented the cosmopolitans, i.e. OTUs shared among all the 13 sites. Green color represented the shared OTUs among two to twelve sites. Dark yellow color represented the endemic OTUs, i.e. the OTUs found exclusively in one site. (A) The network diagram of the surface and subsurface soil fungal communities, (B) The OTUs and sequences proportion for three kinds of OTUs in the two soil layers, (C) The comparison of endemic OTUs and sequences between the surface and subsurface soil. The asterisk means the significant difference between the two layers. 
Fig. 1
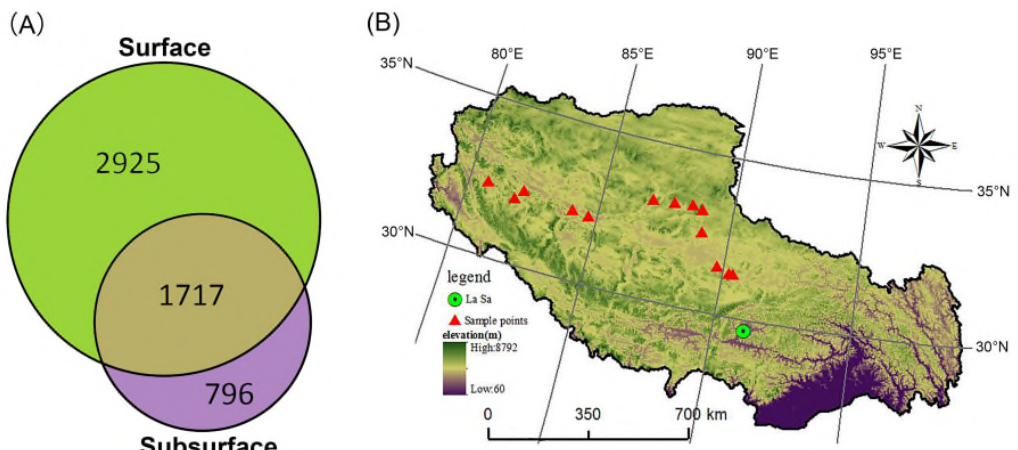

(C)

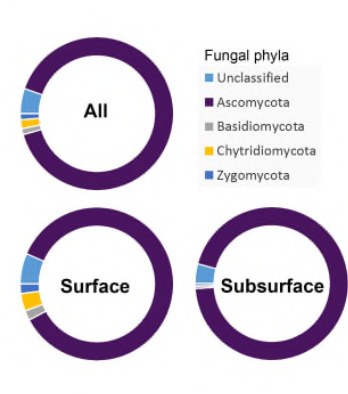


Fig. 2

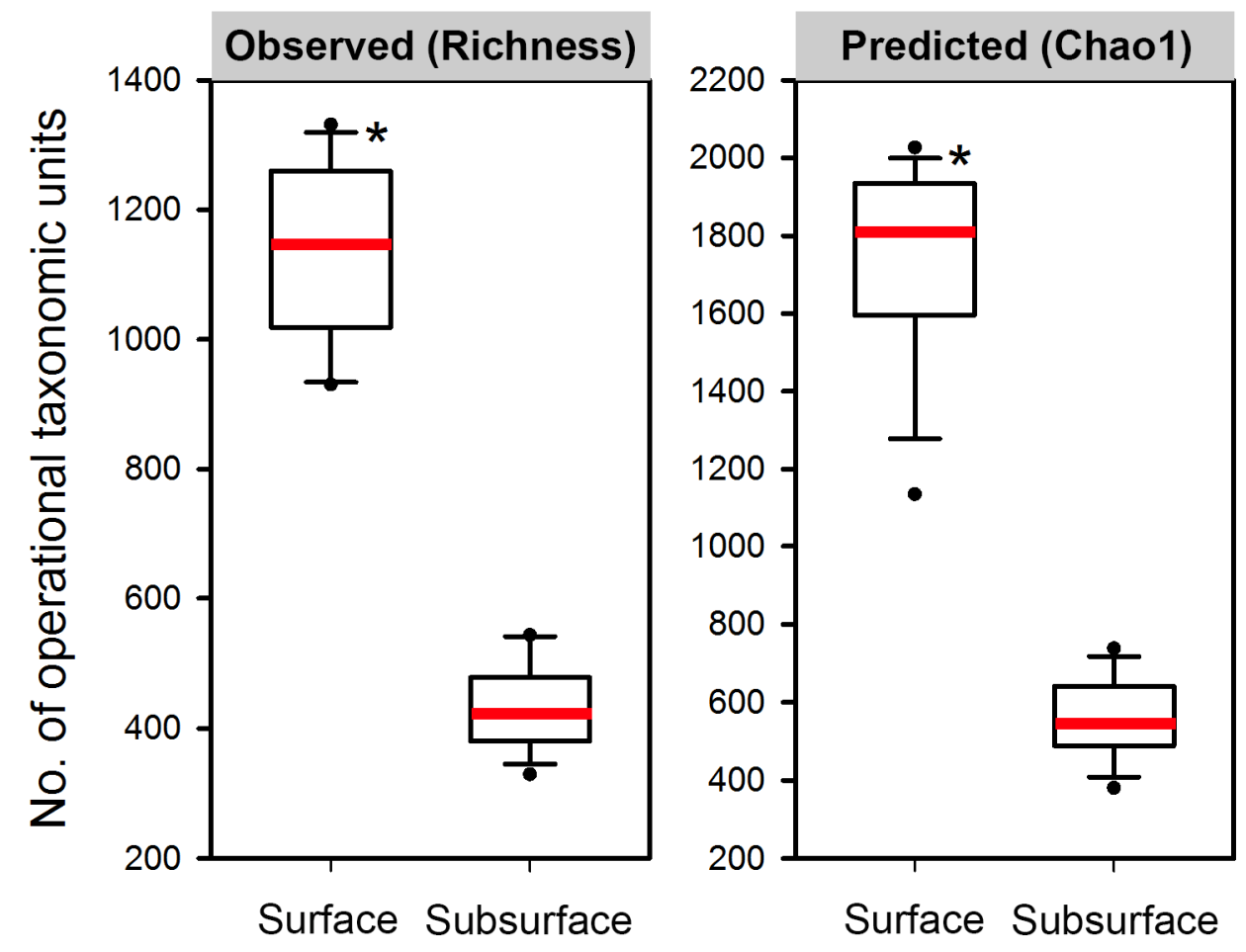


Fig. 3
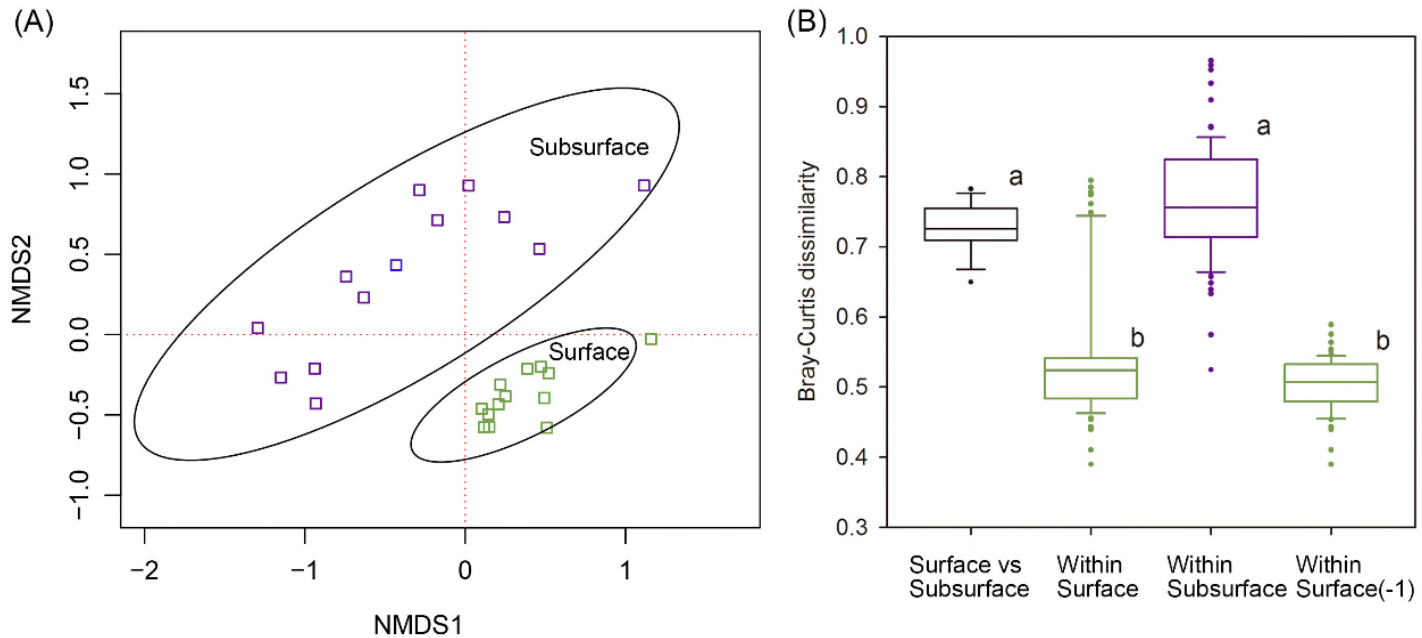
Fig. 4
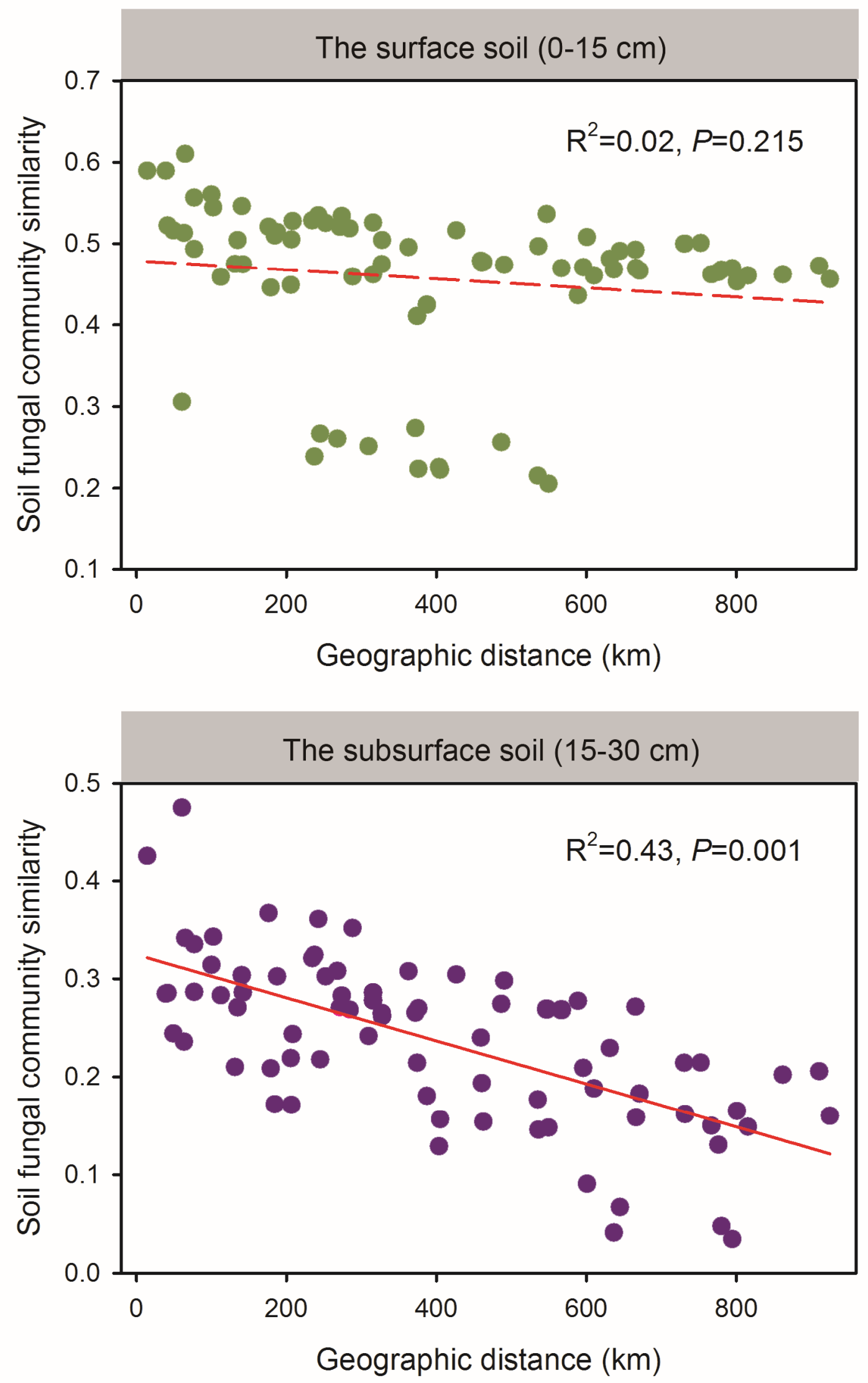
Fig. 5

(A)

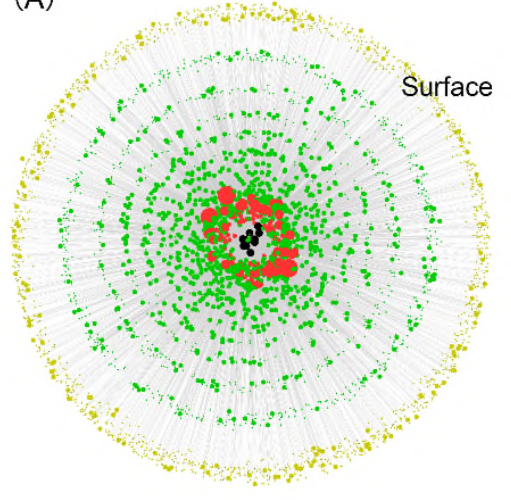

(B)

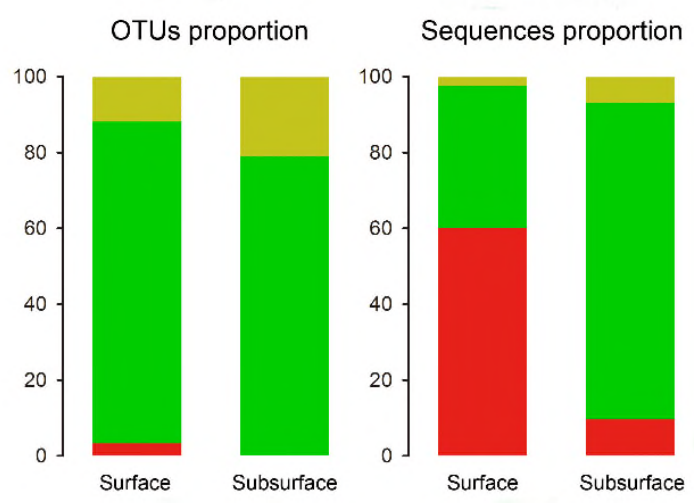

(C)

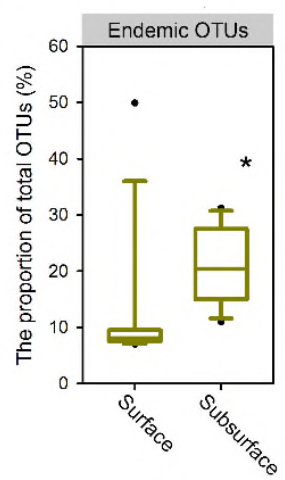

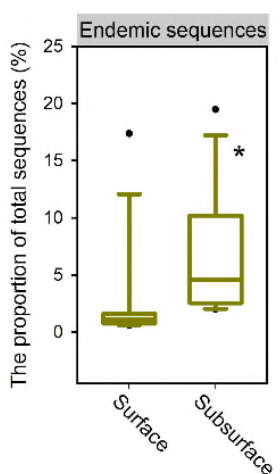


Table 1 The modified Raup-Crick dissimilarity matrices between each site in the surface and subsurface soil based on the null-model expectations.

(A) The surface soil $(0-15 \mathrm{~cm})$

\begin{tabular}{|c|c|c|c|c|c|c|c|c|c|c|c|c|}
\hline Raup-Crick indexes & $1 \mathrm{~A}$ & $2 \mathrm{~A}$ & $3 \mathrm{~A}$ & $4 \mathrm{~A}$ & $5 \mathrm{~A}$ & $6 \mathrm{~A}$ & $7 \mathrm{~A}$ & $8 \mathrm{~A}$ & $9 A$ & $10 \mathrm{~A}$ & $11 \mathrm{~A}$ & $12 \mathrm{~A}$ \\
\hline $2 \mathrm{~A}$ & -1 & & & & & & & & & & & \\
\hline $3 \mathrm{~A}$ & -1 & -1 & & & & & & & & & & \\
\hline $4 \mathrm{~A}$ & -1 & -1 & -1 & & & & & & & & & \\
\hline $5 \mathrm{~A}$ & -1 & -1 & -1 & -1 & & & & & & & & \\
\hline $6 \mathrm{~A}$ & -1 & -1 & -1 & -1 & -1 & & & & & & & \\
\hline $7 \mathrm{~A}$ & -1 & -1 & -1 & -1 & -1 & -1 & & & & & & \\
\hline $8 \mathrm{~A}$ & -1 & -1 & -1 & -1 & -1 & -1 & -1 & & & & & \\
\hline $9 \mathrm{~A}$ & 1 & 1 & 1 & 1 & 1 & 1 & 1 & 1 & & & & \\
\hline $10 \mathrm{~A}$ & -1 & -1 & -1 & -1 & -1 & -1 & -1 & -1 & 1 & & & \\
\hline $11 \mathrm{~A}$ & -1 & -1 & -1 & -1 & -1 & -1 & -1 & -1 & 1 & -1 & & \\
\hline $12 \mathrm{~A}$ & -1 & -1 & -1 & -1 & -1 & -1 & -1 & -1 & 1 & -1 & -1 & \\
\hline $13 \mathrm{~A}$ & -1 & -1 & -1 & -1 & -1 & -1 & -1 & -1 & 1 & -1 & -1 & -1 \\
\hline
\end{tabular}

(B) The subsurface soil $(0-15 \mathrm{~cm})$

\begin{tabular}{|c|c|c|c|c|c|c|c|c|c|c|c|c|}
\hline $\begin{array}{c}\text { Raup-Crick } \\
\text { indexes }\end{array}$ & $1 \mathrm{~B}$ & $2 B$ & $3 B$ & $4 \mathrm{~B}$ & $5 B$ & $6 B$ & $7 B$ & $8 B$ & $9 B$ & $10 \mathrm{~B}$ & $11 B$ & $12 \mathrm{~B}$ \\
\hline $2 B$ & -1 & & & & & & & & & & & \\
\hline $3 B$ & 0.51 & 0.83 & & & & & & & & & & \\
\hline $4 \mathrm{~B}$ & -1 & -1 & 0.9 & & & & & & & & & \\
\hline $5 B$ & -1 & -1 & 1 & -1 & & & & & & & & \\
\hline $6 \mathrm{~B}$ & $\begin{array}{c}- \\
0.26\end{array}$ & -0.1 & $\begin{array}{c}- \\
0.19\end{array}$ & $\begin{array}{c}- \\
0.99\end{array}$ & $\begin{array}{c}- \\
0.97\end{array}$ & & & & & & & \\
\hline $7 B$ & -1 & -1 & 0.5 & -1 & -1 & -1 & & & & & & \\
\hline $8 \mathrm{~B}$ & 0.86 & 0.67 & 0.73 & 0.45 & 0.08 & $\begin{array}{c}- \\
0.36\end{array}$ & $\begin{array}{c}- \\
0.81\end{array}$ & & & & & \\
\hline $9 \mathrm{~B}$ & 1 & 0.98 & $\begin{array}{c}- \\
0.84\end{array}$ & 1 & 0.99 & $\begin{array}{c}- \\
0.07\end{array}$ & $\begin{array}{c}- \\
0.94\end{array}$ & -1 & & & & \\
\hline $10 \mathrm{~B}$ & 0.04 & $\begin{array}{c}- \\
0.25\end{array}$ & -0.5 & 1 & 0.51 & $\begin{array}{c}- \\
0.96\end{array}$ & -1 & -1 & -1 & & & \\
\hline $11 \mathrm{~B}$ & 1 & 1 & 1 & 1 & 1 & 1 & 0.94 & $\begin{array}{c}- \\
0.97\end{array}$ & -1 & 0.07 & & \\
\hline $12 \mathrm{~B}$ & 1 & 1 & 1 & 1 & 1 & 1 & $\begin{array}{c}- \\
0.91\end{array}$ & $\begin{array}{c}- \\
0.97\end{array}$ & -1 & $\begin{array}{c}- \\
0.73\end{array}$ & -1 & \\
\hline $13 B$ & 1 & 0.98 & 1 & 1 & 1 & 1 & $\begin{array}{c}- \\
0.93\end{array}$ & $\begin{array}{c}- \\
0.56\end{array}$ & $\begin{array}{c}- \\
0.93\end{array}$ & $\begin{array}{c}- \\
0.97\end{array}$ & $\begin{array}{c}- \\
0.15\end{array}$ & $\begin{array}{c}- \\
0.65\end{array}$ \\
\hline
\end{tabular}

A represents the 13 samples in the surface soil layer, and $B$ represents the 13 samples in the subsurface soil layer. Positive and negative Raup-Crick indexes represent higher and lower 
dissimilarities between each site compared with the null model expectations, respectively. The values near -1 ( -0.95 to -1$)$ indicate high dispersal, and the values near 1 (0.95 to 1$)$ indicate environmental selection. The values between -0.95 and 0.95 indicate ecological drift. 


\section{Supplementary Tables and Figures}

\section{Table S1 - Table S5}

Fig. S1 - Fig. S3

\section{References}

Table S1 The variation in the relative abundances of fungal phyla between different soil depth.

Surface $(0-15 \mathrm{~cm}) \quad$ Subsurface $(15-30 \mathrm{~cm}) \quad P$ values of t- test

\begin{tabular}{lccc}
\hline Ascomycota & $85.75 \pm 13.34$ & $94.78 \pm 3.95$ & $\mathbf{0 . 0 0 7}$ \\
Chytridiomycota & $3.72 \pm 12.92$ & $0.03 \pm 0.10$ & 0.160 \\
Basidiomycota & $2.07 \pm 2.16$ & $0.51 \pm 1.20$ & $\mathbf{0 . 0 0 1}$ \\
Zygomycota & $1.99 \pm 1.99$ & $0.50 \pm 1.23$ & $<\mathbf{0 . 0 0 1}$ \\
\hline
\end{tabular}

Values are the means $\pm S D, n=26$. The test method was the independent $t$-test, which was done after the arcsine-sqrt transformation of the original relative abundance data. The significant $P$ values were in bold. 
Table S2 BLAST-based taxonomic affinity of the ten most abundant OTUs detected in the surface and subsurface soil.

\begin{tabular}{|c|c|c|c|c|c|}
\hline \multirow{2}{*}{$\begin{array}{c}\% \\
\text { Abundance }\end{array}$} & \multicolumn{5}{|c|}{ Best blast match to NCBI-nr database } \\
\hline & $\begin{array}{c}\text { GenBank } \\
\text { no. }\end{array}$ & Coverage & $\begin{array}{c}\% \\
\text { Identity }\end{array}$ & Definition & Ecological niche \\
\hline \multicolumn{6}{|c|}{ Surface soil $(0-15 \mathrm{~cm})$} \\
\hline 4.68 & KT991134 & 97 & 99 & Pseudeurotium sp. & Soil in Fildes Peninsula, Antarctic \\
\hline 4.62 & KR261446 & 100 & 100 & $\begin{array}{l}\text { Penicillium } \\
\text { flavigenum }\end{array}$ & Soil in Brazil \\
\hline 3.97 & KU612322 & 100 & 100 & Alternaria sp. & $\mathrm{BSC}^{\mathrm{a}}$ in an arid grassland, America \\
\hline 3.47 & AF216757 & 100 & 96 & $\begin{array}{l}\text { Spizellomyces } \\
\text { acuminatus }\end{array}$ & Grassland soil in America \\
\hline 2.79 & NR_138294 & 100 & 99 & Penicillium elleniae & Leaf litter in Colombia \\
\hline 2.78 & KJ443251 & 100 & 100 & Penicillium sp. & Alkaline soil in Russia \\
\hline 2.31 & KX394541 & 100 & 100 & Fusarium tricinctum & Arthropod cadaver in America \\
\hline 1.88 & LT603041 & 100 & 100 & Didymella glomerata & $\begin{array}{l}\text { Surface of volumes from an archive of } \\
\text { the University of Milan in Italy }\end{array}$ \\
\hline 1.66 & KT269499c & 99 & 100 & Helotiales sp. & $\begin{array}{l}\text { Surface-sterilized, asymptomatic } \\
\text { roots of Microthlaspi in France }\end{array}$ \\
\hline 1.32 & KT269651 & 100 & 99 & Helotiales sp. & $\begin{array}{l}\text { Surface-sterilized, asymptomatic } \\
\text { roots of Microthlaspi in France }\end{array}$ \\
\hline \multicolumn{6}{|c|}{ Subsurface soil (15-30 cm) } \\
\hline 12.51 & $K X 438348^{d}$ & 100 & 100 & Tetracladium sp. & Roots of Quercus robur in Poland \\
\hline 6.32 & $K X 394541^{b}$ & 100 & 100 & Fusarium tricinctum & Arthropod cadaver in America \\
\hline 3.68 & KT269499c & 99 & 100 & Helotiales sp. & $\begin{array}{l}\text { Surface-sterilized, asymptomatic } \\
\text { roots of Microthlaspi in France }\end{array}$ \\
\hline 3.24 & KX011011 & 100 & 100 & Geomyces sp. & Sub-glacial soil in India \\
\hline 2.74 & KT269946 & 98 & 98 & Cadophora sp. & $\begin{array}{l}\text { Surface-sterilized, asymptomatic } \\
\text { roots of Microthlaspi in Greece }\end{array}$ \\
\hline 2.7 & KT269651 & 100 & 99 & Helotiales sp. & $\begin{array}{l}\text { Surface-sterilized, asymptomatic } \\
\text { roots of Microthlaspi in France }\end{array}$ \\
\hline 2.69 & HG935225 & 100 & 100 & Tetracladium sp. & Zea mays roots in Germany \\
\hline 2.65 & KP160169 & 100 & 97 & Uncultured fungus & Orchid roots in Belgium \\
\hline 2.11 & KU538619 & 100 & 98 & Uncultured fungus & $\begin{array}{l}\text { The Cacti Microbiome in semi-arid } \\
\text { region in Mexico }\end{array}$ \\
\hline 2.02 & KX610348 & 100 & 100 & $\begin{array}{l}\text { Pseudogymnoascus } \\
\text { sp. }\end{array}$ & $\begin{array}{l}\text { Cave Soils in El Malpais National } \\
\text { Monument, New Mexico, America }\end{array}$ \\
\hline
\end{tabular}


The three OTUs in bold were the shared dominant OTUs in the surface and subsurface soil. Coverage and similarity were derived from the results of the default megablast in NCBI Basic Local Alignment Search Tool. Every dominant OTU accounted for more than $1 \%$ of the sequences.

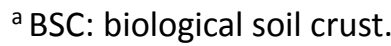

${ }^{b}$ The seventh dominant OTU in the surface soil was also assigned to uncultured fungus clone (KU536886) from the Cacti Microbiome on semi-arid region in Mexico (Fonseca-Garcia et al., 2016) with the same scores.

c The ninth dominant OTU in the surface soil was also assigned to uncultured fungus clone (KU537482) from the Cacti Microbiome on semi-arid region in Mexico (Fonseca-Garcia et al., 2016) with the same scores.

${ }^{d}$ The first dominant OTU in the subsurface soil was also assigned to uncultured fungus (KX776493) from orchid roots in Belgium (Esposito et al., 2016), or uncultured Tetracladium (HG935228) from Zea mays roots in Germany (Moll et al., 2016). 
Table S3 Description of soil physicochemical properties of different soil layers in each site.

\begin{tabular}{|c|c|c|c|c|c|c|c|c|c|}
\hline $\begin{array}{l}\text { Sample } \\
\text { code }\end{array}$ & Soil layer & $\mathrm{pH}$ & $\begin{array}{c}\mathrm{SC} \\
\text { (us/cm) }\end{array}$ & $\begin{array}{c}\text { SM } \\
\text { (W/W\%) }\end{array}$ & $\begin{array}{l}\text { TC } \\
(\%)\end{array}$ & $\begin{array}{l}\text { TN } \\
(\%)\end{array}$ & $\begin{array}{l}\mathrm{C}: \mathrm{N} \\
\text { ratio }\end{array}$ & $\begin{array}{c}\text { DOC } \\
(\mathrm{mg} / \mathrm{kg})\end{array}$ & $\begin{array}{c}\text { DTN } \\
(\mathrm{mg} / \mathrm{kg})\end{array}$ \\
\hline P01-A & Surface & 8.51 & 97.5 & 10.43 & 0.95 & 0.14 & 6.86 & 84.8 & 14.36 \\
\hline P02-A & Surface & 8.49 & 40.3 & 11 & 1.49 & 0.19 & 7.71 & 65.1 & 15.74 \\
\hline P03-A & Surface & 9.01 & 86.6 & 8.4 & 2.92 & 0.07 & 44.43 & 63.8 & 5.55 \\
\hline P04-A & Surface & 8.48 & 72.1 & 8.72 & 2.33 & 0.16 & 14.27 & 164.9 & 9.5 \\
\hline P05-A & Surface & 8.62 & 77.4 & 6.64 & 1.88 & 0.14 & 13.68 & 94.5 & 15.96 \\
\hline P06-A & Surface & 8.55 & 127.2 & 8.63 & 2.66 & 0.21 & 12.83 & 152.8 & 18.31 \\
\hline P07-A & Surface & 8.69 & 86.9 & 4.53 & 2.42 & 0.07 & 32.65 & 264.5 & 8.5 \\
\hline P08-A & Surface & 8.92 & 76.7 & 1.4 & 1.13 & 0.02 & 56.61 & 98.4 & 9.07 \\
\hline P09-A & Surface & 8.85 & 114.6 & 9.04 & 3.52 & 0.1 & 35.93 & 140.9 & 5.68 \\
\hline P10-A & Surface & 9.04 & 148.1 & 8.11 & 3.66 & 0.13 & 27.37 & 271.7 & 11.38 \\
\hline P11-A & Surface & 8.21 & 933 & 7.72 & 5.31 & 0.14 & 37.06 & 244.6 & 12.33 \\
\hline P12-A & Surface & 8.66 & 114 & 5.31 & 1.71 & 0.09 & 19.87 & 272.8 & 5.35 \\
\hline P13-A & Surface & 8.41 & 27.9 & 3.33 & 0.37 & 0.04 & 8.33 & 48.5 & 8.67 \\
\hline P01-B & Subsurface & 8.43 & 59.6 & 9.9 & 0.75 & 0.1 & 7.29 & 45.8 & 9.1 \\
\hline P02-B & Subsurface & 8.6 & 88.1 & 7.47 & 0.87 & 0.08 & 10.24 & 75.9 & 6.05 \\
\hline P03-B & Subsurface & 8.95 & 119.1 & 8.39 & 3.1 & 0.06 & 48.12 & 109.9 & 3.81 \\
\hline P04-B & Subsurface & 8.55 & 95.1 & 10.68 & 2.26 & 0.11 & 21.51 & 543 & 5.6 \\
\hline P05-B & Subsurface & 8.58 & 109.7 & 11.35 & 2.85 & 0.15 & 19.38 & 61.7 & 6.02 \\
\hline P06-B & Subsurface & 8.63 & 121.2 & 9.91 & 2.67 & 0.15 & 17.61 & 152.3 & 8.11 \\
\hline P07-B & Subsurface & 8.61 & 93.1 & 6.87 & 3.03 & 0.07 & 45.19 & 125 & 5.62 \\
\hline P08-B & Subsurface & 8.91 & 115.4 & 4.25 & 1.17 & 0.03 & 45.21 & 246.9 & 3.32 \\
\hline P09-B & Subsurface & 8.74 & 133.1 & 8.99 & 3.97 & 0.11 & 36.19 & 272 & 4.35 \\
\hline P10-B & Subsurface & 8.98 & 120.8 & 4.19 & 2.96 & 0.04 & 65.89 & 219.4 & 3.92 \\
\hline P11-B & Subsurface & 8.61 & 557 & 6.22 & 5.92 & 0.1 & 57.04 & 111.6 & 6.38 \\
\hline P12-B & Subsurface & 8.28 & 124.4 & 6.05 & 2.28 & 0.09 & 26.64 & 27.1 & 4.86 \\
\hline P13-B & Subsurface & 8.55 & 74.9 & 2.7 & 0.46 & 0.06 & 7.98 & 119.7 & 5.27 \\
\hline
\end{tabular}

SC: soil conductivity, SM: soil moisture, TC: soil total carbon, TN: soil total nitrogen, DOC:

dissolved organic carbon, DTN: dissolveed total nitrogen. 
Table S4 The correlations $(r)$ and significance $(P)$ were determined by Pearson analysis between soil fungal richness and environmental variables.

\begin{tabular}{lcccccc}
\hline & \multicolumn{2}{c}{ All } & \multicolumn{2}{c}{ Surface } & \multicolumn{2}{c}{ Subsurface } \\
\hline Variables & $r$ & $P$ & $r$ & $P$ & $r$ & $P$ \\
pH & -0.09 & 0.658 & -0.52 & 0.067 & 0.08 & 0.808 \\
Soil conductivity & -0.01 & 0.971 & -0.09 & 0.767 & -0.47 & 0.105 \\
SM & -0.02 & 0.939 & 0.26 & 0.399 & -0.12 & 0.700 \\
TC & -0.11 & 0.579 & -0.18 & 0.556 & -0.36 & 0.230 \\
TN & 0.34 & 0.088 & 0.40 & 0.179 & -0.14 & 0.655 \\
C:N ratio & -0.3 & 0.131 & -0.57 & $\mathbf{0 . 0 4 3}$ & -0.28 & 0.361 \\
DOC & -0.06 & 0.783 & -0.16 & 0.598 & 0.13 & 0.681 \\
DTN & $\mathbf{0 . 6 9}$ & $\mathbf{0 . 0 0 1}$ & 0.44 & 0.135 & -0.21 & 0.500 \\
MAT & -0.11 & 0.605 & -0.52 & 0.068 & -0.18 & 0.551 \\
MAP & 0.03 & 0.872 & 0.20 & 0.519 & -0.01 & 0.271 \\
PET & -0.12 & 0.548 & $-\mathbf{0 . 5 9}$ & $\mathbf{0 . 0 2 6}$ & -0.24 & 0.430 \\
Aridity & 0.08 & 0.686 & 0.41 & 0.16 & 0.07 & 0.823 \\
NPP & 0.06 & 0.786 & 0.17 & 0.057 & 0.31 & 0.304 \\
\hline Almeans & & & & & &
\end{tabular}

All means 26 soil samples including the surface soil and subsurface soil. Surface means the surface soil at the depth of $0-15 \mathrm{~cm}$, and subsurface means the subsurface soil at the depth of 15$30 \mathrm{~cm}$. SM: soil moisture, TC: total carbon, TN: total nitrogen, DOC: dissolved organic carbon, DTN: dissolved total nitrogen, MAT: mean annual temperature, MAP: mean annual precipitation, PET: potential evapo-transpiration, NPP: net primary productivity. The significant $P$ values were in bold. 
Table S5 The correlations $(r)$ and significance $(P)$ were determined by Mantel test between soil fungal community composition and environmental variables.

\begin{tabular}{lcccccc}
\hline & \multicolumn{2}{c}{ All } & \multicolumn{2}{c}{ Surface } & \multicolumn{2}{c}{ Subsurface } \\
\hline Variables & $r$ & $P$ & $r$ & $P$ & $r$ & $P$ \\
pH & -0.05 & 0.679 & 0.10 & 0.282 & -0.01 & 0.478 \\
Soil conductivity & -0.01 & 0.504 & -0.06 & 0.39 & $\mathbf{0 . 5 2}$ & $\mathbf{0 . 0 0 2}$ \\
SM & 0.07 & 0.236 & 0.05 & 0.341 & $\mathbf{0 . 2 4}$ & $\mathbf{0 . 0 4 2}$ \\
TC & 0.16 & 0.08 & 0.14 & 0.167 & $\mathbf{0 . 4 1}$ & $\mathbf{0 . 0 0 4}$ \\
TN & -0.14 & 0.938 & -0.08 & 0.57 & -0.13 & 0.818 \\
C:N ratio & $\mathbf{0 . 1 7}$ & $\mathbf{0 . 0 2 9}$ & 0.15 & 0.105 & $\mathbf{0 . 2 5}$ & $\mathbf{0 . 0 3 7}$ \\
DOC & 0.06 & 0.357 & -0.09 & 0.683 & 0.01 & 0.398 \\
DTN & -0.04 & 0.608 & 0.04 & 0.383 & 0.08 & 0.248 \\
MAT & 0.09 & 0.107 & 0.18 & 0.1 & 0.20 & 0.054 \\
MAP & 0.05 & 0.256 & -0.02 & 0.394 & 0.19 & 0.099 \\
PET & 0.14 & 0.052 & $\mathbf{0 . 2 8}$ & $\mathbf{0 . 0 1 6}$ & $\mathbf{0 . 3 5}$ & $\mathbf{0 . 0 1 3}$ \\
Aridity & $\mathbf{0 . 1 5}$ & $\mathbf{0 . 0 3 4}$ & 0.15 & 0.187 & $\mathbf{0 . 5 0}$ & $\mathbf{0 . 0 0 2}$ \\
NPP & 0.01 & 0.453 & 0.09 & 0.208 & -0.09 & 0.742 \\
\hline Almeans & & & & & &
\end{tabular}

All means 26 soil samples including the surface soil and subsurface soil. Surface means the surface soil at the depth of $0-15 \mathrm{~cm}$, and subsurface means the subsurface soil at the depth of 15 $30 \mathrm{~cm}$. SM: soil moisture, TC: total carbon, TN: total nitrogen, DOC: dissolved organic carbon, DTN: dissolved total nitrogen, MAT: mean annual temperature, MAP: mean annual precipitation, PET: potential evapo-transpiration, NPP: net primary productivity. The significant $P$ values were in bold. 

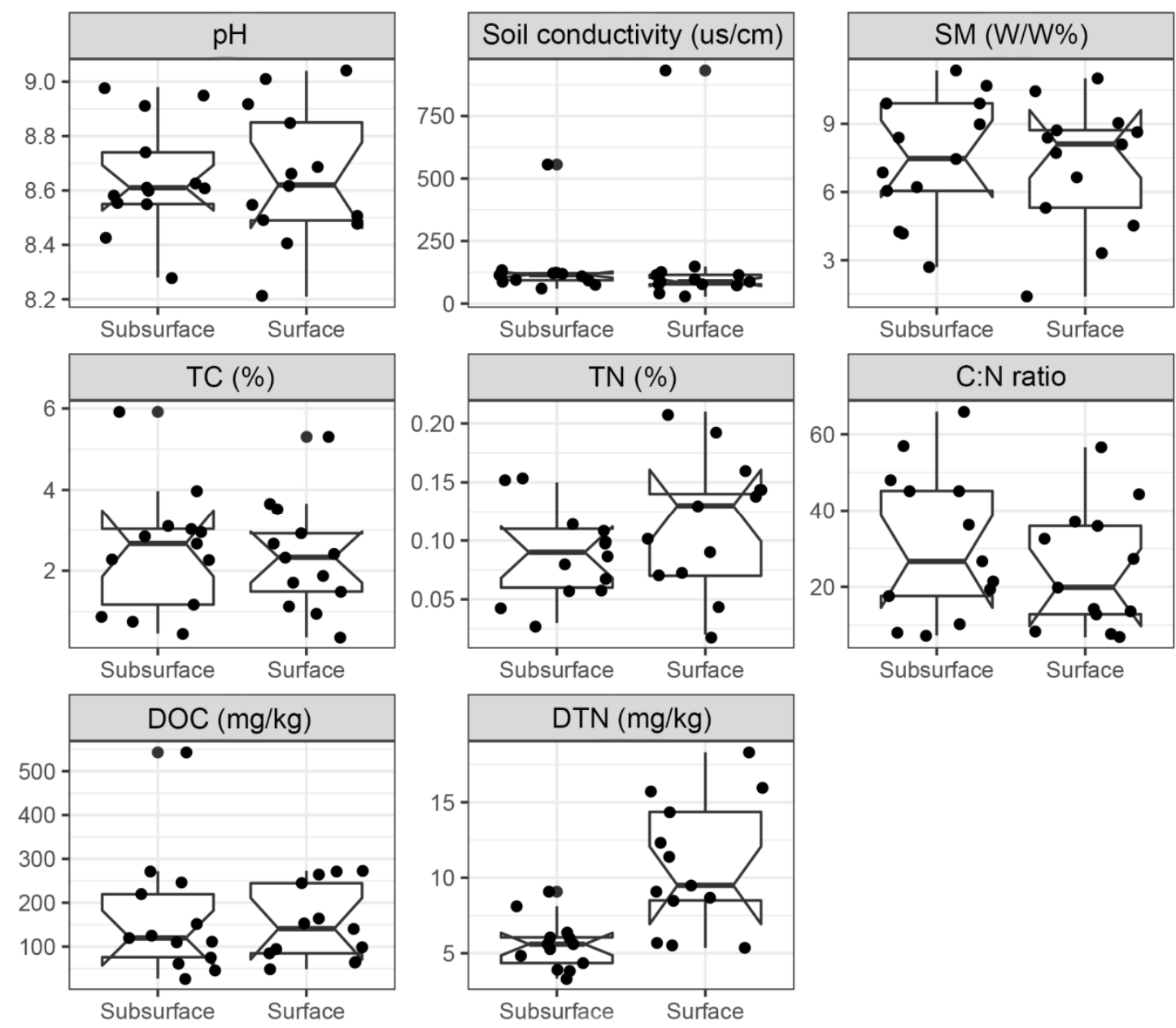

Fig. S1. The variation in soil properties between the surface and subsurface soil layers. Only DTN (dissolved total nitrogen) was significant different between the surface and subsurface soil layers, which was tested by the Independent $\mathrm{t}$-test $(P=0.001)$. SM: soil moisture, TC: total carbon, $\mathrm{TN}$ : total nitrogen, DOC: dissolved organic carbon. 

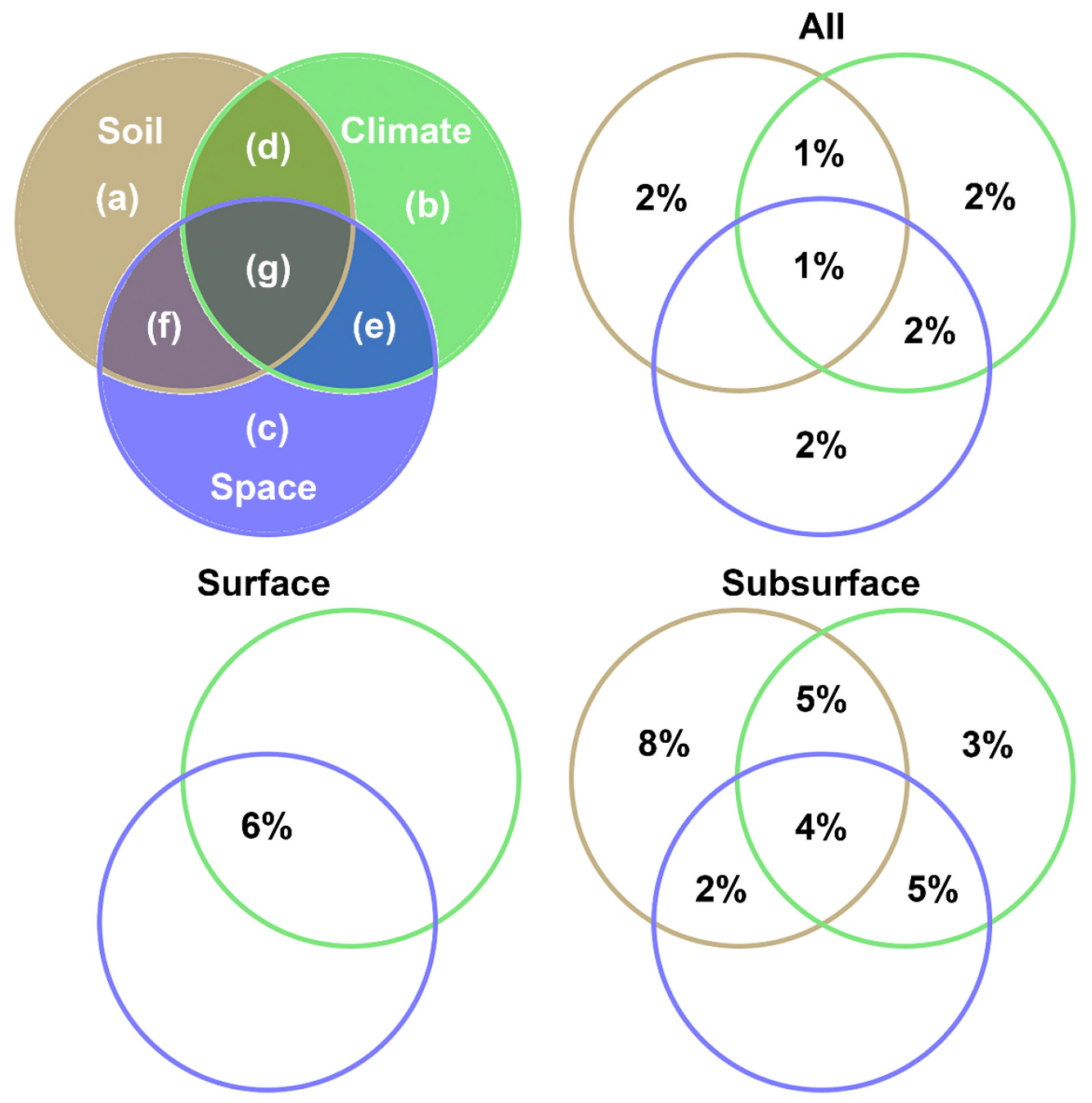

Fig. S2. Venn diagram of variation partitioning analysis, showing the effects of soil, climate and space on fungal community composition in different soil layers. Because soil properties did not significantly affect fungal community composition in the surface soil, only two cycles were shown for the surface-soil Venn diagram. 


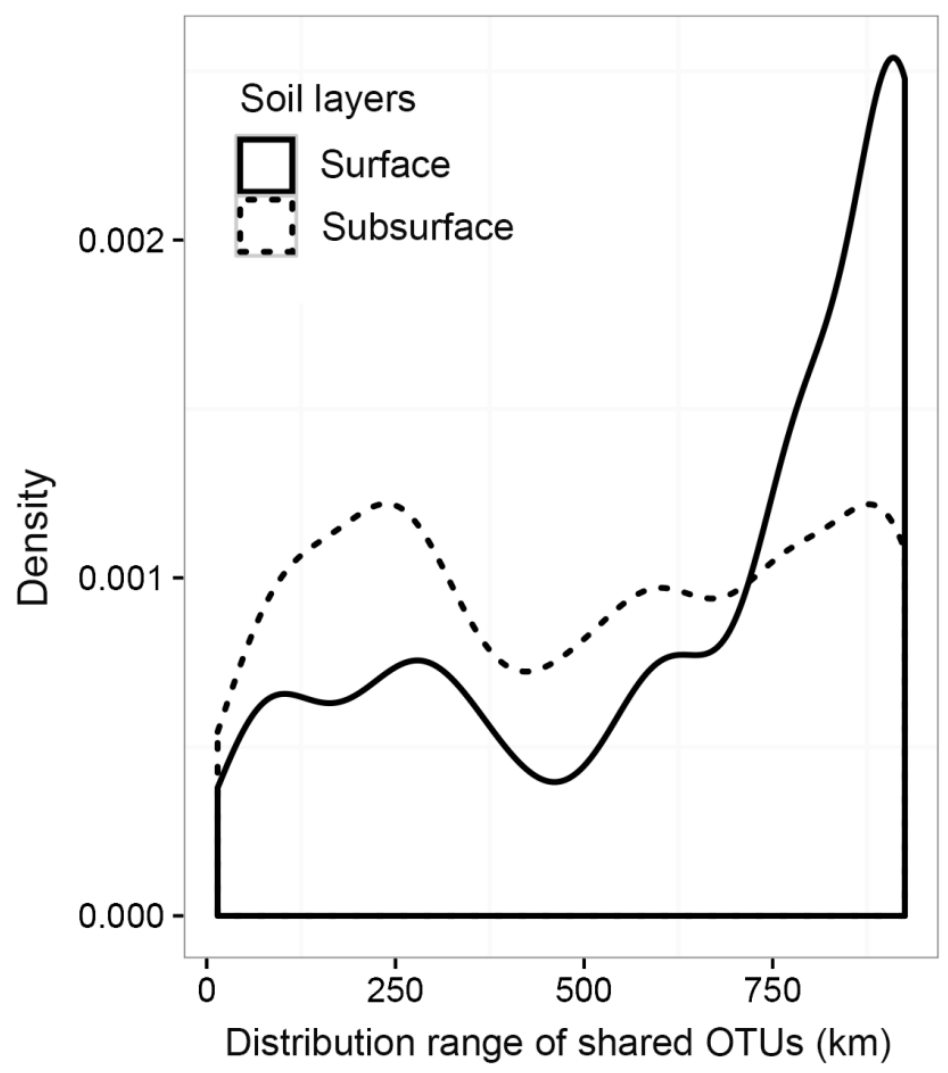

Fig. S3. The density plot of the distribution range of shared OTUs in the surface and subsurface soil. The shared OTUs are the fungal OTUs observed in $2 \sim 12$ sites in the surface and subsurface soil, respectively. 


\section{References}

Esposito, F., Jacquemyn, H., Waud, M., and Tyteca, D. (2016) Mycorrhizal fungal diversity and community composition in two closely related platanthera (Orchidaceae) species. Plos One 11: e0164108.

Fonseca-Garcia, C., Coleman-Derr, D., Garrido, E., Visel, A., Tringe, S.G., and Partida-Martinez, L.P. (2016) The cacti microbiome: interplay between habitat-filtering and host-specificity. Frontiers in Microbiology 7: 150.

Moll, J., Hoppe, B., Konig, S., Wubet, T., Buscot, F., and Kruger, D. (2016) Spatial distribution of fungal communities in an arable soil. Plos One 11: e0148130. 